\title{
LOS PROYECTOS DE INTEGRACIÓN SOCIAL DEL INDIO Y EL IMAGINARIO NACIONAL DE LAS ELITES INTELECTUALES GUATEMALTECAS, SIGLOS XIX Y XX*
}

POR

\author{
MARTA E. CASAUS ARZÚ
}

Profesora titular de Historia de América Universidad Autónoma de Madrid

En este artículo se exponen con cierto rigor las tesis de algunos de los pensadores políticos del siglo XIX y XX, en torno a los proyectos de nación incluyentes o excluyentes de los grupos subalternos, indios o ladinos.

Se analizan a lo largo del siglo XIX las posiciones más incluyentes, representadas por José Cecilio del Valle; 'o las excluyentes, Batres Jáuregui y se analiza el proceso por el cual estas tesis siguen perdurando hasta el momento actual.

Se pueden encontrar defensores de la exclusión en Horacio Altamirano o de la inclusión, Juárez Muñoz, durante el primer cuarto del siglo XX.

El análisis de algunos pensadores de la llamada Generación del 20 permea todo este artículo y representa un novedoso análisis y una veta de trabajo realmente importante para comprender cuáles han sido algunos de aquellos argumentos que se siguen utilizando incluso en el presente; para seguir sosteniendo las teorías de la exclusión o inclusión de los indígenas en el proyecto de nación guatemalteco.

Los cambios sustanciales que se contemplan en los Acuerdos de Paz firmados en Guatemala el 29 de diciembre de 1996, especialmente aquellos acuerdos sustantivos como el de Identidad y Derechos de los Pueblos Indígenas, el Acuerdo sobre Fortalecimiento del Poder Civil y función del Ejército en una Sociedad Democrática o el de Aspectos Socio-Económicos y Situación Agraria, abrieron un filón de esperanza a la sociedad civil y permitieron crear nuevos espacios de interculturalidad y participación ciudadana, durante el gobierno del presidente Alvaro Arzú. Buena parte de esos Acuerdos iban a ser sometidos a ratificación en un referéndum celebrado, el 16 de mayo de 1999, para reformar la Constitución e

* Trabajo realizado dentro del Proyecto de Investigación PB97-1125 (DGES) 
incorporarlos a la Carta Magna. La respuesta mayoritaria de la escasa población que ejerció el voto, un $18.55 \%$ (9,4\%), fue «no»a las enmiendas constitucionales.

La polémica y el debate generado por dichas reformas, especialmente por aquellas que abordan el tema de la multiculturalidad y la definición de la nación, y las consecuencias jurídicas y políticas que de estas reformas se derivaban, ha generado una vez más una fractura en la sociedad que se ha reflejado en un fuerte enfrentamiento entre elites indígenas y ladinas, sectores urbanos y rurales, iglesia católica e iglesias neopentecostales, polémica en la que ha triunfado el voto del miedo, del racismo y la intolerancia, contribuyendo a cerrar los espacios del diálogo, la democracia y la interculturalidad.

Las razones esgrimidas en la mayor parte de los medios de comunicación, talleres y seminarios, han sido mayoritariamente de carácter jurídico o de índole étnico-racial. Han sido escasas las argumentaciones de carácter político o social. El debate, en ocasiones se ha convertido en una agria polémica de descalificaciones mutuas, provocando la emergencia de viejos fantasmas coloniales, sobre el temor hacia el indio, el peligro de la guerra étnica, la defensa de la ladinidad.

La discusión entre escritores y periodistas mayas y ladinos ha llegado a tal nivel de virulencia y desencuentro, en posiciones que deberían de ser comunes para el conjunto de la ciudadanía, que nos obliga a reflexionar, una vez más, acerca de la construcción de una identidad nacional, que al margen de ser una realidad aún lejana, constituye un problema sin resolver y cuyas raíces hay que buscarlas en la historia, para entender por qué la construcción de la nación y el problema del indio es un asunto nacional no cerrado que cada cierto tiempo surge en la arena política, se expresa en las tertulias, en los debates del congreso y en los medios de comunicación y finalmente termina languideciendo, sin encontrar una solución de consenso para el conjunto de la población, así como hallar nuevas fórmulas de incorporación de los mayas a la nación.

En este artículo nos parece interesante recuperar el pasado y analizar cuáles fueron los diferentes imaginarios nacionales desde finales del siglo XIX y principios del XX, por qué no se consiguió pensar en un proyecto de nación homogénea por la vía del mestizaje y cuáles fueron las principales causas de la exclusión política del indígena del Estado y de la nación. En qué medida existieron algunos intentos de revalorización de lo autóctono y por qué los elementos singularizadores e integradores de las culturas autóctonas fueron escasos durante el proceso de construcción de la identidad nacional.

En palabras de Quijada ${ }^{1}$, en el péndulo de la exclusión entre el pasado indígena y el hispánico, para el caso de Guatemala, los ladinos, criollos o blancos, siempre se inclinaron por la búsqueda de las raíces hispánicas, negando o invisi-

1 Sobre el tema de la singularización de la patria y de la nación y el imaginario de la emancipación, François-Xavier GuerRa y Mónica QuiJADA, ( Coords.) Imaginar la Nación, MunsterHamburgo, AHILA, 1994, p.34.

R. I., $1999, \mathrm{n}^{\circ} 217$ 
bilizando todo el pasado indígena o considerándolo un pueblo en decadencia y una raza degenerada incapaz de redimirse por la vía de la educación, de la civilización o del mestizaje.

Frente a las escasas voces que, en la década de 1920, se alzaban a favor de la regeneración del indio a través de la civilización o de su redención mediante la educación, eran más las que abogaban por una solución eugenésica considerando que el indio era irredimible, al que no se podría regenerar porque pertenecía a una raza inferior ${ }^{2}$.

Antes de entrar a plantear nuestras hipótesis e intentar buscar elementos explicativos de la realidad social y política en el pensamiento del siglo XIX y XX, resulta conveniente situar los principales argumentos de la discusión en la actualidad. No son más que el reflejo de un debate inacabado sobre el indio y la nación, que se inicia desde la Colonia, continúa durante el período de la Ilustración, se profundiza con la Independencia, se intenta buscarle una solución en torno a 1870 , se produce un giro durante la década de 1920 y vuelve a ser objeto de discusión, a partir de 1996, con motivo de la firma de los Acuerdos de Paz, pero especialmente a raíz de las campañas para el referéndum sobre las reformas constitucionales.

Los puntos centrales de la polémica corresponden a distintos grupos sociales, algunos de carácter étnico y que a su vez reflejan las diferentes corrientes de pensamiento y opciones políticas que pueden inscribirse en cuatro variantes:

La representada por los intelectuales mayas, de diversas organizaciones del movimiento, quienes parten del supuesto de que Guatemala posee un Estado ladino y racista, que ha sufrido un proceso de colonialismo interno hegemonizado por los ladinos y por la élite dirigente, que han acaparado el poder político desde la Independencia y no ha sido capaz de reconocer las diferencias étnico-culturales del pueblo maya,. Ha elaborado un proyecto criollo ladino de nación, cuya finalidad es el exterminio de la población indígena, la asimilación a la cultura ladina o la integración por la vía de la ladinización con la pérdida de su cultura y de su identidad ${ }^{3}$.

A pesar de las diferencias entre grupos de intelectuales mayas, la mayoría critica los esfuerzos del grupo ladino por conseguir una homogeneización racial y

2 Marta E. CASAuS ARZU, «Las elites intelectuales y la generación del 20 en Guatemala: su visión del indio y su imaginario de nación», Ponencia presentada en LASA, Chicago, septiembre, 1998.

3 Demetrio CoJTI Cuxil, Configuración del pensamiento político del Pueblo Maya, Quetzaltenango, Asociación de escritores Mayas, 1991. Del mismo autor, Ri Maya Moloj Pa Iximulew, El movimiento maya en Guatemala, Guatemala, Cholsamaj, 1997. Sam ColOP, Cinco siglos de Encubrimiento, Guatemala, SPEM, 1991. Jorge SOLARES, Estado y nación : las demandas de los grupos étnicos en Guatemala, Guatemala, Flacso, 1993. 
cultural mediante la educación, la aculturación o la ladinización. Consideran las nuevas estrategias de mestizaje cultural o hibridación maniobras ladinas asimilacionistas e integradoras, que no respetan la identidad y la cultura del Otro.

A juicio de estas elites mayas, las causas históricas de esta situación hay que buscarlas en la colonización española y la política de hispanización, en el colonialismo interno, en los efectos del racismo, como mecanismo de explotación económica, de desidentificación o desvalorización de la cultura indígena y de exclusión social. Responsabilizan de esta situación al proyecto ladinocéntrico de educación homogeneizadora, como vehículo de integración y asimilación. Estos autores denuncian al Estado liberal por racista, ladino, etnocéntrico, excluyente y responsable posterior de las masacres y el terrorismo de Estado desatado contra los mayas en la década de 1980.

Si bien es verdad que existen notables diferencias entre las elites intelectuales mayas en el planteamiento de la solución y las propuestas de construcción de una nación multi o intercultural, así como hay divergencias en torno a las vías de incorporación de la población indígena a la plena ciudadanía, en un nuevo contexto jurídico y político, no parece haber mucho disenso en lo que respecta a las causas históricas, sociales y políticas que provocaron el conflicto armado y el genocidio de la población indígena. Las diferencias son de matiz entre aquellos que enfatizan los aspectos étnico culturales o los que refuerzan la relación de clase 4 .

La otra corriente ideológica está representada por un grupo social, en su mayoría ladino urbano, que, frente a la emergencia y posicionamiento del movimiento maya, reacciona de forma visceral y virulenta argumentando que la identidad maya es una elucubración o una falsedad y que como tal no existe, ya que los mayas se extinguieron en el siglo IX, con la decadencia de su civilización Afirman que dicha identidad obedece a una construcción etnonacionalista, destinada a arrebatarle el poder a los ladinos y dividir el Estado.

A juicio de estos autores, el movimiento pan-maya es anti ladino y esencialista, posee su origen en intelectuales foráneos norteamericanos y franceses que crearon una identidad étnica imaginaria y que ahora las elites mayas pretenden aprovechar para obtener fondos internacionales, organizarse mejor y desplazar a los ladinos del poder 5 .

Rechazan la pureza étnica del movimiento maya y abogan por un proyecto de nación mestiza, argumentando que el ladino es un mestizo biológico y cultural y

4 Sobre las diferencias entre mayas populares y culturales, en función de su participación en organizaciones con énfasis en los derechos étnicos y culturales o en las organizaciones de clase o revolucionarias, véase los trabajos de, Santiago BASTOS y Manuela CAMUS. Abriendo caminos, Guatemala, Flacso, 1995. Víctor GALVEZ BorRel et all, ¿Qué sociedad queremos? Una mirada desde el movimiento y las organizaciones mayas, Guatemala, Flacso,1997.

5 El mejor exponente de esta posición es Mario Roberto MORALES «La identidad y la patria del ladino» en Claudia DARY, ( Comp.) La construcción de la Nación y la representación ciudadana en México, Guatemala; Ecuador y Bolivia, Guatemala, Flacso, 1998.p. 449 y sigs. 
que, por ende, debe reivindicar su ladinidad construyendo un movimiento panladino que ponga freno al movimiento maya y que negocie en términos de fuerza, las bases económicas y políticas de la nueva nación.

Morales considera que el ladino es el representante de la nación guatemalteca y que frente a la irrupción del mayismo, debe fortalecer su identidad, su cultura, su protagonismo histórico y prepararse para una negociación, para una guerra étnica o para la división o balcanización del país.

Estas dos posiciones enfrentadas, estas dos construcciones identitarias binómicas apuntan hacia dos formas de intentar fundamentar la legitimidad del Estado en dos proyectos excluyentes de imaginar la nación. Excluyentes en la medida en que ambos pretenden negar al Otro, su derecho a la diferencia, a la cultura y a la plena incorporación. Esencialistas porque ambos pretenden hacer valer sus marcadores o sus señales identitarias como las únicas válidas para el conjunto de la población. Opuestas no, en la medida en que ambos proyectos están fundamentados en una concepción étnico-cultural y pretenden fundamentar su identidad en términos exclusivamente étnicos. Ambos grupos, conformados en su mayoría por indígenas y ladinos, pretenden buscar la solución a través del establecimiento de pactos étnicos y no de pactos sociales y políticos. En ambos casos el énfasis del derecho a la diferencia está por encima de la búsqueda de lo que hay de común en ambos grupos, una ciudadanía común y diferenciada.

Una posición intermedia es la que mantienen un colectivo de historiadores y antropólogos ladinos, en su mayor parte, que, desde una posición más intelectual, con argumentaciones más académicas, plantean la existencia de un proyecto de nación ladina desde el siglo XIX, durante el cual el Estado buscó homogeneizar a la población mediante la ladinización. Este proyecto obedeció a la idea de que los ladinos se encontraban en un estadio más cercano a la civilización y resultaba más fácil incorporarlos al Estado que las poblaciones indígenas.

Consideran que el ladino es una construcción política del siglo XIX y que tratar de cambiar el binomio ladino -indígena por el de mestizo- maya implica caer en el relativismo cultural, porque el ladino no es una identidad cultural homogénea, ni una etnia ni un pueblo, además de que mestizo y ladino nunca fue lo mismo en Guatemala 6 .

Para Taracena, a partir de la Constitución de 1879, los liberales decidieron modificar por vía legal el Estado tripolar en materia étnico-cultural compuesto por criollos, ladinos e indios, en un Estado bipolar de indios y ladinos. Lo ladino

\footnotetext{
6 Para Rodas, el ladino pasó a ser una entidad política definida por el Estado y no debe definirse en función de términos culturales, étnicos, sino en función de su identidad política o de clase. «El ladino una identificación política del siglo XIX», Guatemala. Instituto de Investigaciones, Escuela de Historia, USAC, 1997. En esta línea se encuentran otros trabajos, como los de Claudia SAMAYOA, «Pueblo ladinos? Reflexiones en torno a la reconstrucción de la Guatemala pluricultural, multilingüe y multiétnica,. Documento presentado en el Congreso de la República de Guatemala, 16 de octubre,1998.(mimeo).
}

R. I., $1999, \mathrm{n}^{\circ} 217$ 
se constituyó como un frente no indígena en el que cabían todas las identidades menos los indígenas. Para él, el mestizaje no tuvo lugar en Guatemala más que durante la revolución de 1944 y fue abortada 7 .

A mi juicio, estos autores tratan de buscar los elementos singularizadores de la nación desde la óptica de lo ladino en sus diferentes variantes, política, cultural, de clase, pero en ningún caso lo ponen en relación con la matriz étnica ni hacen referencia a las relaciones interétnicas, al conflicto histórico social de ambos grupos, a la estructura social y menos a los espacios de sociabilidad y al mestizaje cultural, fruto de la relación. Ninguno de ellos aborda el tema desde la larga duración ni considera la importancia del racismo como un hecho clave para entender la configuración de la sociedad y del Estado guatemalteco. Creo que estos autores, que realizan un gran aporte desde la óptica de la historia o de la antropología, parten de una visión ladinocéntrica de la historia sin llegar a articular los conceptos de etnia, clase y nación en sus planteamientos.

Mi punto de vista como ciudadana guatemalteca, mestiza- ladina, que le preocupa profundamente el destino de su país y ve con esperanza los cambios que podían derivarse del cumplimiento de los Acuerdos de paz, difiere de los planteamientos anteriores y ha creado bastante polémica, en los últimos años en el mundo académico ${ }^{8}$. Uno de los problemas más graves de las elites intelectuales guatemaltecas fue su incapacidad de pensar y construir, en un momento de su historia, un proyecto de nación mestiza. Considero que uno de los mayores déficit de legitimidad del Estado guatemalteco actual, parte del fracaso del proyecto liberal homogéneo a lo largo de todo el siglo XIX. Tampoco se aprovechó esa oportunidad en la década 1920 y 1930, durante las dictaduras de Estrada Cabrera y de Ubico, porque los pensadores de esas generaciones estuvieron muy influidos por el positivismo y las corrientes racialistas. La influencia de pensadores como José Ingenieros u Octavio Bunge fue mayor que la de autores mexicanos como Justo Sierra o Molina Enríquez y Pimentel.

Durante este período, el discurso hegemónico fue el de la eugenesia, la regeneración de las razas o la redención del indio. El rechazo al mestizaje y su desvalorización como raza inferior, degradada o degenerada, fue uno de los elementos que obstaculizó la creación de un proyecto de integración mediante el mestizaje. Esta toma de posición que se reflejó en un largo debate en la prensa, el Congreso y las universidades obstaculizó la creación de una conciencia de identidad nacional y volvió a excluir al indígena de la nación.

7 Arturo TARACENA ARRIOLA, «Guatemala y sus retos, desde la óptica de un historiador político, en Momento, $n$. 1, Guatemala ASIES,1999. «La élite intelectual y el renovamiento regionalista altense, 1880-1930» en la Ermita, n.4/13, Guatemala, marzo 1999.

8 Marta CASAus ARZU, «Reflexiones en torno a la legitimidad del Estado, la nación y la identidad en el marco de los Acuerdos de Paz en Guatemala», Boletín de lingüística, Guatemala Universidad Rafael Landívar, 1998. 
Es durante este período histórico en donde nuestro proyecto se aleja sustancialmente del mexicano, costarricense o nicaragüense y nuestros imaginarios nacionales se encuentran más cercanos al cubano, boliviano o peruano 9 .

Ante el escaso éxito del proyecto liberal integrado de ladinización, las elites intelectuales de las décadas de 1920 y 1930, rehuyen plantear un modelo de homogeneización política y proponen la eugenesia como fórmula de uniformidad racial. La herencia del liberalismo decimonónico sigue viva en nuestra imagen de nación actual y la mayor parte del pensamiento ladino, marxista y no marxista, se mueve en términos de integración por medio de la ladinización o proletarización; por la fagocitación de la cultura del otro o de la aculturación unidireccional. Son escasos los autores que plantean la incorporación plena del indígena a la ciudadanía; es más, comparando el debate de la prensa de la década de 1920 y el de estos últimos meses, el discurso de primeros de siglo era más incluyente e integrador que el actual.

Las posibilidades de integración o asimilación, por medio de la ladinización o de la redención por la educación, daba mayores oportunidades, desde una óptica paternalista o humanitaria en los años treinta, que la visión de las elites intelectuales en la actualidad ${ }^{10}$.

Por ello considero importante volver la mirada hacia el debate que se generó en la década de 1920 y en los antecedentes de éste, en la segunda mitad del siglo XIX, sobre la integración y asimilación del indígena durante este período, por considerar que gran parte de los planteamientos actuales se encuentran anclados en el pasado. Pretendemos dar soluciones en el presente, con argumentos propios del Despotismo Ilustrado, del liberalismo decimonónico o del pensamiento racial del la década de 1920.

9 Consuelo NARANJo OROVIO, «Cuba 1898 : Reflexiones en torno a la continuidad y a los imaginarios nacionales», Cuadernos de Historia Contemporánea(Dossier: 1898: España fin de siglo) Madrid, 1998, pp. 221-234. Mónica QuIJADA, «De la Colonia a la República: inclusión, exclusión y memoria histórica en el Perú, en Histórica, Vol.XVIII, n.2, Diciembre,1994, pp. 365282. Marta IRUROZQUI, La armonía de las desigualdades, Elites y conflictos de poder en Bolivia, Madrid, Consejo Superior de Investigaciones Científicas, Madrid, Cuzco, Centro de Estudios Regionales Andinos, 1994.

10 Tomando una muestra amplia de unos 30 artículos al azar, de los principales diarios y revistas nacionales durante los meses de febrero a mayo de 1999, con objeto de analizar los argumentos sobre la consulta popular para las reformas constitucionales, podemos confirmar que los argumentos del NO son mayoritarios y la mayor parte de ellos están referidos a imposibilidad e ilegalidad de incluir los derechos étnicos y culturales en la constitución. La temática étnica y multicultural es el punto principal de rechazo de las reformas. Sin embargo en la prensa de los años 1920 y 1930, se produce un rico debate en los diarios de la época sobre la necesidad de redimir, integrar, o incorporar a los indígenas a la nación.

R. I., $1999, \mathrm{n}^{\circ} 217$ 

XIX

La preocupación de la Monarquía Hispana por la integración del indio a las instituciones coloniales resulta un hecho evidente, plasmado en toda la legislación indiana. Como antecedente, para el caso de Guatemala, resulta interesante conocer cuál era el modelo de integración, quiénes eran los agentes de cambio, qué vehículos jurídico-políticos consideraban más apropiados y cuál era su percepción del indio. Desde la primera época colonial encontramos la preocupación por parte de la Iglesia y de la Corona por cristianizar e hispanizar a los indígenas.

La propuesta del Oidor Tomás López, que llegó a Guatemala a mediados del siglo XVI, recoge dos vías de asimilación, que estarán presentes en todas las propuestas de las elites criollas, aunque supone un cierto distanciamiento de la política del momento. Plantea el inconveniente de que los indios y españoles vivan separados en Repúblicas, dado que ello supone un gran obstáculo para la castellanización. Propone la asimilación, mediante matrimonios con campesinos pobres y atrasados de la Península de las indias de la nobleza indígena, que tuvieran dote, para darles a aquéllos al menos un incentivo material ${ }^{11}$. De esta forma los indígenas podrán aprender «nuestra policía, de comer, beber, vestir, de limpiarnos y tratar a nuestras personas....y finalmente nuestra lengua que es lo que pretendemos» ${ }^{12}$. A este fin, elabora una serie de ordenanzas prohibiendo el uso de los idiomas naturales, el abandono de sus patronímicos y, por supuesto, un rápido proceso de conversión, insistiendo en que el elemento fundamental es la castellanización ${ }^{13}$. Esta política deberá llevarla a cabo la Iglesia, pero también los maestros en las escuelas, y serán de gran ayuda los matrimonios mixtos.

Todas las recomendaciones de López, excepto la relacionada con los matrimonios mixtos, se plasmaron posteriormente en las Ordenanzas de 1551 y 1554 , en varias Cédulas Reales en 1561 y 1565, que fueron luego retomadas por los oidores y visitadores Juan de Maldonado y Paz en las Ordenanzas de 1625 y Antonio Lara Mogrovejo en $1647^{14}$.

\footnotetext{
11 «Sería cosa acertada que V.A. mandase algunos labradores, gente simple y llana de Sayago....que no desdeñen en poblar entre estos indios y habitar con ellos y trabar matrimonio con las hijas destos y aun enviarles algunas mozas de esta suerte y condición para casarlas con algunos de estos caciques... Carta al Rey de Tomas López, oidor del reino de Guatemala, AGI, 9a, 25 de marzo de 1551.

12 Carta del Oidor Tomas López, AGI, 1551.

13 «Y por todo esto tengo entendido que hasta que no se conviertan en nuestra lengua....es imposible, al menos muy dificultoso, su enseñamiento, porque, si no oyen ¿cómo creeran?» AGI, 1551.

14 En estas se restringen gran parte de las manifestaciones artísticas y culturales de los indígenas bajo penas corporales, como cárceles, cepos o trasquilamientos a las indias. AGI, Audiencia de Guatemala, 9a, 1647
}

\section{R. I., $1999, \mathrm{n}^{\circ} 217$}


Son innumerables los peninsulares, criollos y religiosos que propusieron diferentes modelos de aculturación e integración de los indígenas a la sociedad hispana, Antonio Fuentes y Guzmán, el obispo Marroquín y el Arzobispo Cortés y Larranz, el presidente de la Audiencia López Cerrato. Casi todos ellos ponen el énfasis en la religión, como principal canal de aculturación y supresión de la cultura por bárbara y salvaje. Parten del reconocimiento del derecho natural, al considerar a los indígenas como bárbaros, seres extraños o ajenos a cultura propia y a la civilización. Ello no suponía que estuvieran exentos de derechos.

Como opina Clavero, el status que se les va a dar a los indígenas con carácter general durante toda la Colonia, es el mismo que recibieron en la Península Ibéri$\mathrm{ca}$, el de rústico, persona miserable o menor ${ }^{15}$. Sin embargo son escasos los autores que abogan por una fusión o interacción entre indígenas y españoles o entre criollos e indígenas, al menos mediante el matrimonio y una propuesta de mestizaje biológico y cultural, como lo hace Tomás López. Casi siempre el proceso de aculturación se piensa de forma unidireccional y la integración del indio se concibe como una asimilación con pérdida de su identidad y de su cultura.

No obstante los resultados del período colonial son dispares, pero podemos afirmar que, para el caso de Guaemala el modelo asimilacionista fue poco exitoso en términos generales y se produjo paulatinamente, sobre todo en el siglo XVII, un proceso de recuperación de las identidades étnicas y de reforzamiento de las culturas locales ${ }^{16}$.

El Despotismo Ilustrado supuso un nuevo imaginario de integración del indígena, basado en otros supuestos filosóficos ${ }^{17}$. Los filósofos como movimiento, como élite intelectual de la época, con sus nuevos ideales o valores acerca de la ciencia y la experiencia, del utilitarismo, de la libertad y la felicidad, de la nueva concepción del paganismo y de nuevas formas de gobierno, como el republicanismo, causaron un profundo impacto en las elites criollas centroamericanas y especialmente guatemaltecas.

15 Para B. Clavero este triada de rústico, miserable y menor, en cuanto a legislación, obtiene unos beneficios positivos por su tutela, pero también tiene sus aspectos negativos. De cualquier forma era un status con tratamiento propio, con sus propios privilegios, de ahí que las Leyes de Indias le den un tratamiento de favor. Clavero lo denomina «status de etnia» Bartolomé Clavero, Derechos indígenas y cultura constitucional en América, México, Siglo XXI, 1994.

16 Para el caso de México, Nancy FARRISS, Los sociedad maya bajo el dominio colonial, Madrid, Alianza Editorial, 1992. Marcello CARMAGNANI, El regreso de los dioses. El proceso de reconstitución de las identidades étnicas en Oaxaca, siglos XVII y XVIII, México, Fondo de Cultura Económica, 1988. Para Guatemala, Marta Elena CASAUS, «Cambios y continuidades de las elites caqchikeles en el altiplano guatemalteco, 1524-1600», Leipzig, X Congreso de AHILA, septiebre,1993. Carol SMITH, (edit), Guatmalan Indians and State, 1540-1988, Austin, University of Texas Press, 1990.

17 Peter GAY, The Enlightment. An interpretation. The rise of modern paganism. N.W. Nrton and Company, 1977. Isaiah BERLIN, The Age of Enlightment. The eighteenth century Phiposophers, Oxford University Press, 1979. 
Figuras como Domingo Juarros, Antonio Larrazábal, José y Juan José de Aycinena, Gregorio Urruela y José Cecilio del Valle, van a estar muy influidos por el pensamiento ilustrado español y especialmente por figuras de gran relevancia local, como Fray José Antonio de Liendo y Goicoechea. ${ }^{18}$ El estudio del pensamiento ilustrado estará muy vinculado a la Universidad de San Carlos y a las elites criollas y peninsulares que van a jugar un papel determinante en la emancipación Centroamericana.

Estas nuevas elites que podemos dividir en tres generaciones de 1800 a 1830 , se encuentran vinculadas a nuevas instituciones como la Sociedad Económica de Amigos el País, el Consulado de Comercio, a la vez que poseen el control de los Ayuntamientos y de los principales diarios, La Gazeta de Guatemala y posteriormente El Amigo de la Patria y El Editor Constitucional ${ }^{19}$.

Es la Sociedad de Amigos del País, en 1796, la que va a proponer un concurso sobre, «Las utilidades de que todos los indios y ladinos se vistan y calcen a la española y medios de conseguirlo sin violencia, coacción ni mandato». Este ensayo causó tal polémica en su momento y tuvo tantos detractores que se ha llegado a pensar que la Sociedad de Amigos del País fue suprimida a causa de esta iniciativa. El premio recayó sobre un fraile dominico, Fray Matías de Cordova.

$\mathrm{El}$ ensayo parte de una serie de considerandos que, a juicio del autor, comparte con una serie de «hombres ilustrados de Guatemala», a los que les preocupa la situación de los indios, mulatos y mestizos, en la medida en que están alejados de la necesidad y de la felicidad En la medida en que están al margen de la sociedad no desarrollan el mutuo vínculo de la necesidad y de ahí parten todos sus vicios morales, el ocio, la apatía, la ignorancia, la depravación, etc.

Para Matías de Córdova, la integración de los indios es más necesaria para los criollos que para ellos mismos, que viven en un estado salvaje, al margen de la sociedad «sin necesidades». Para que adquieran esas necesidades del bien común y para que sean conscientes de la utilidad de vivir en sociedad, es necesario que calcen y vistan a la usanza española, porque de esta forma se les integrará al comercio, en las artes y buenas costumbres, adquirirán necesidades físicas y nue-

18 Este fraile de la orden franciscana nació en Costa Rica en 1735 y murió en Guatemala en 1814. Llevó a cabo una profunda reforma en la Universidad de San Carlos y su plan fue aprobado por la Corona e implantado en todas las universidades de la Península. Introdujo las ciencias experimentales, la física y la química y los estudios de semiótica. Canalizó las ideas ilustradas y las teorías de la ciencia moderna.

19 Sobre la adaptación de las ideas ilustradas a Centroaméric, Adolfo BonILLA, «The Central American Enlightment, 1770-1838, An interpretation of political ideas and political history», tesis doctoral, Manchester, 1996. Teresa GARCIA GIRALDEZ., «Los espacios de la patria y la nación en el proyecto político de José Cecilio del Valle», en Anuario de Estudios Centroamericanos, San José, Costa Rica, Universidad de Costa Rica, 1996, pp.41-81. Elisa LuQue AlCAIDE, La Sociedad Económica de Amigos del país de Guatemala, Sevilla, Escuela de Estudios Hispanoamericanos, 1962.

R. I., 1999, n. $^{\circ} 217$ 
vas virtudes ${ }^{20}$. Para Córdova el vehículo de aculturación no son las leyes, ni el mestizaje o ladinización, ni la coacción física o moral, sino el convencimiento y la persuasión ya que, gracias a la imitación y la educación cívica, sin violencia ni mandato, podrán alcanzar la virtud.

Los agentes sociales del cambio serán los Alcaldes Mayores y los curas, «que tiene gran influjo sobre los indios», pero también deberán contar con los Alcaldes indígenas y los acólitos que darán ejemplo al resto de la población. Este proyecto será liderado por aquellos hombres ilustrados que, vinculados a la Sociedad Económica de Amigos del País, deberán promover e influir en el gobierno local para que se lleve a cabo esta iniciativa. Efectivamente, años mas tarde, la sociedad Económica de Amigos del País vuelve a convocar varios concursos buscando fórmulas de asimilar e hispanizar a la población indígena. Valle lo comenta en varios de sus escritos y sus propuestas coinciden bastante con las del despotismo ilustrado de la época.

\section{EL PROYECTO DE NACIÓN Y LA VISIÓN DEL INDIO EN EL PENSAMIENTO POLÍTICO DE JOSÉ CECILIO DEL VALLE Y DE ANTONIO BATRES JÁUREGUI.}

José Cecilio del Valle y Díaz del Valle pertenece a una red familiar criolla vinculada por sus relaciones matrimoniales y de negocios con toda la región centroamericana, especialmente con Honduras, Guatemala y El Salvador. Ocupa cargos públicos en la Administración colonial, es Auditor de Guerra, Auditor honorario del Ejército, Fiscal interino. En su calidad de funcionario, participa en la elaboración del Acta de Independencia. Durante la anexión de Guatemala a México es elegido miembro de la primera Junta Provincial Consultiva del gobierno federal de Centroamérica. Dirige primero, El Amigo de la Patria y luego El Redactor General y es también autor de varios ensayos.

Fue uno de los pensadores políticos centroamericanos más relevantes del primer tercio del siglo XIX. Representa la figura del científico, que mantiene relaciones epistolares con intelectuales extranjeros de la talla de Jeremías Bentham, a quien le une una gran amistad y de su intercambio surgen publicaciones propias y de otros autores. Estuvo muy influido por el pensamiento ilustrado español, especialmente por Jovellanos y Campomanes.

Antonio Batres Jáuregui nace en la segunda mitad del siglo XIX, es un hombre imbuido del liberalismo de la época y gran conocedor de los pensadores europeos, como Spencer, Mills, Guizot, Buckle, Bancroft y Darwin. Admirador del

20 A juicio de Matías de Córdova «si el indígena estuviera vestido como los españoles, siendo natural la imitación, aprenderían sus costumbres y cotejando la sinceridad, la honestidad, la suavidad del trato... emprenderían estas virtudes aunque no fuera mas que por preciarse de hombre culto» p. 110.

R. I., $1999, \mathrm{n}^{\circ} 217$ 
pensamiento ilustrado español de Jovellanos y Campomanes, a quienes cita constantemente en el tema de la modernización de la agricultura. Dirigió la secretaría de la Sociedad de Amigos del País durante dieciocho años y enseñó Economía Política, Derecho Internacional y Literatura. Fue un gran abogado, historiador, filólogo y político. Fue diputado durante varias legislaturas en 1879 y 1897. Contribuyó a la redacción de varios textos constitucionales, durante los gobiernos liberales de Barrios y Lisandro Barillas ${ }^{21}$.

Valle y Batres Jáuregui representan el pensamiento de las elites criollas y se hacen portavoces de dichos proyectos. Ambos se hallan a caballo de sus respectivos siglos, presencian momentos de grandes transformaciones y toman posición ante ellos.

Siguiendo la tipología de Quijada ${ }^{22}$, y aplicándola al caso de Guatemala consideramos que Valle representa el modelo de «nación cívica» y Batres, más influido por el pensamiento de Sarmiento, el de «nación civilizada». ${ }^{23} \mathrm{Ambos}$ creen que el progreso tiene que pasar indefectiblemente por la asimilación del indio, asimilación por fusión, en el caso de Valle y de integración mediante la ladinización, en el caso de Batres. Ambos autores se encuentran muy influidos por el despotismo ilustrado español, especialmente Valle, mientras Batres, como hombre de su tiempo, se empapa del positivismo comtiano.

En el pensamiento de Valle, el imaginario de la nación aparece como una construcción incluyente, donde la heterogeneidad y la falta de cohesión desaparecen gracias a instituciones benéficas y a una educación orientada a la formación de ciudadanos. La dimensión institucional se superpone a la cultural, frenando la tendencia centrípeta de la diversidad mediante la cohesión fundada en la identidad global de la «ciudadanía».

El concepto de inclusión «por fusión» o de asimilación va a ser el modelo más común en todos los pensadores centroamericanos de la primera mitad del

21 Las redes familiares de los Batres y los Valle, constituyen parte de las elites de poder de más larga duración y de mayor influencia en Guatemala. Los Batres emparientan con familias vascas y son los Delgado de Nájera el principal nicho de ubicación . Por su extensión, capacidad de alianzas y notoriedad es una de las familias criollas que genera mayor número de intelectuales: Manuel y José Batres Arrivillaga, Pedro y Francisco Batres Nájera y sobre todo Antonio Batres Jáuregui, uno de los intelectuales más importantes del siglo XIX, que junto con Antonio Larrazábal Arribillaga, José Cecilio del Valle y Juan José de Aycinena Piñol fueron los artífices de un proyecto político de las elites criollas, fungiendo, por lo tanto de «intelectuales orgánicos» de su grupo durante los siglos XVIII y XIX. La función de estos intelectuales consistió en reelaborar y adaptar el pensamiento europeo al espacio americano; sirvieron de portavoces de su grupo para legitimarse en el poder y lucharon por mantener la hegemonía, asegurando de este modo la supervivencia de su red familiar. Marta E. CASAUS ARZu, Guatemala, linaje y racismo,, San José, Costa Rica, Flacso, 1992 (reed.1995). Teresa GARCIA GIRALDEZ, Las emigración vasca a Centroamérica.. Las redes familiares como estructuras de poder en Guatemala, Madrid, Universidad Autónoma, 1993.

22 QUIJADA [1].

23 Idem.

R. I., $1999, \mathrm{n}^{\circ} 217$ 
siglo XIX. La influencia del despotismo ilustrado se mezcla con un liberalismo incipiente, del que Valle es uno de sus mejores exponentes. El proyecto de nación en Valle se construye desde arriba, desde las instituciones, lo llevan a cabo miembros de la élite criolla, porque son los que están legitimados para indicar los tiempos y los pactos que es necesario sellar, relativos a las dimensiones de la integración de dichos sectores sociales y a los niveles que se deben realizar, de modo que el nuevo proyecto de nación engloba a los sectores que menos riesgos comportan al proyecto.

En cambio, el proyecto de nación de Batres es más excluyente, obedece a un intento de homogeneizar a la población indígena, mediante la educación, para integrarla en la ciudadanía y así incorporarla a la economía a través del nuevo cultivo de exportación: el café. A mi juicio, lo que el liberalismo pretende, durante la segunda mitad del siglo XIX, es sentar las bases ideológicas para justificar, dentro del binomio barbarie-civilización, la exclusión del indio de la nación. Para ello se hacía necesario asimilarlo, convertirlo en ladino y propietario, e integrarlo en la cultura occidental mediante la educación «civilizadora», intentando despojarle de sus idiomas y su cultura. Durante la segunda mitad del siglo XIX civilización y occidentalización van a ser dos caras de la misma moneda.

En Centroamérica como en otras partes de América Latina, la nueva organización del espacio político y social, que surge de la coyuntura independentista, trata de adaptar y reelaborar los conceptos de patria y nación y de definir dentro de ella el lugar que corresponde al indio, que adquiere una importancia relevante por la presencia de grupos étnicos que son mayoritarios en la población ${ }^{24}$. El tema del indio constituye una de las constantes preocupaciones de las elites criollas, la conveniencia de su inclusión o exclusión y el papel que debe jugar como ciudadano con plenos derechos, sea súbdito o bárbaro con estatuto restringido, vuelve a ser un tema de interés como lo había sido durante toda la época colonial y como lo será a partir de 1920 .

La patria y la nación que proyectan Valle y Batres no son idénticas: en Valle dominan las ideas ilustradas y en Batres las del liberalismo decimonónico. En ambos el peso recae sobre la educación, sólo que concebida de manera diferente. Para Valle es el sector de la élite caracterizado por su sabiduría, el que ha de poner todos los medios a su alcance para integrar al resto de los grupos socioraciales. Para Batres, sin despojarse del todo de las ideas ilustradas, son el Estado y las constituciones quienes deben ejercer las transformaciones en la sociedad, como lo analizaremos a continuación.

24 GARCIA GIRALDEZ [19]. Entiende por inclusión «por fusión» la integración en la que concurren los aspectos mejores de cada cultura, también la indígena. 
LOS ESPACIOS DE LA PATRIA Y LA NACIÓN EN EL PROYECTO POLÍTICO DE JOSÉ CECILIO DEL VALLE Y DE ANTONIO BATRES JÁUREGUI.

Valle, siguiendo la tendencia general de los pensadores de la independencia, prefiere utilizar el término patria al de nación y elige este término para titular del periódico que dirige a partir de 1820, El Amigo de la Patria, en el que incorpora los debates políticos y constitucionales de Europa y América.

El origen de la palabra patria es más viejo que el de otras que se utilizan en el discurso ilustrado o liberal de la época. Quijada sostiene que se prefiere el término «patria» porque es más fácil de identificar; se apoya en el territorio, el lugar de nacimiento y el vínculo de lealtad que este hecho despierta. Hace referencia a un soporte físico y no a una derivación filosófica del pensamiento humano. «La América es mi patria y todo ciudadano debe amar la que tenga»... siendo Guatemala mi patria de origen, de domicilio y de elección» ${ }^{25}$. Esta doble lealtad política de sentirse centroamericano y guatemalteco, es un hecho común en los libertadores y un elemento constante en la obra de Valle. La idea de patria chica y patria grande está presente a lo largo de su vida ${ }^{26}$. Además de lugar de origen y sentimiento para Valle, patria es también felicidad y libertad, en el sentido revolucionario propio de la independencia; deseo de ruptura de los vínculos que tratan de impedir el progreso. La patria es amor a la libertad, aplicándose el término patria a la tierra de hombres libres y por tanto felices.

Aunque Valle prefiere utilizar el término patria, a menudo recurre al de nación, utilizándolos indistintamente. Nación es un término más complejo, posee varios significados; además del territorial, el cultural y el institucional. En el aspecto cultural, Valle llama nación a cada uno de los grupos étnicos colocados bajo el dominio centralizador castellano, à las naciones de los Zutujiles, Kichees, Sapotitlecos, Choles, Kacchiquees ò Guatimalas» ${ }^{27}$.

Para Batres la nación por antonomasia es España, pero también llama «nación» a los reinos mayas, en cuanto comunidades organizadas, con un cierto grado de civilización. Un elemento en Batres, que coincide con las observaciones de Hale y Quijada para otros países de América Latina, es la utilización del término de nación o pueblo vinculado a una etnia. Cuando Batres se está refiriendo a los grupos étnicos Quichés o Caqchikeles, los considera naciones y hace la distinción entre tribus bárbaras y naciones civilizadas. Resulta clara la utilización del concepto de nación colonial para describir a los distintos grupos étnicos que habitaban el territorio de Guatemala, pero a su vez emplea ese mismo concepto para las tribus idólatras y salvajes que habitaban las provincias de Centroamérica a la

25 El Amigo de la Patria, $\mathrm{n}^{\circ} 18$ y 19, T. 2, fol. 139, Guatemala, 30 de noviembre de 1821.

26 Sobre este tema véase T. GARCIA GIRALDEZ [19]. Virgilio RodRIGUEZ BETETA, Ideologías de la Independencia, Guatemala, Educa, 1926.

27 El Amigo [25].

R. I., 1999, n. ${ }^{\circ} 217$ 
llegada de los españoles. La diferencia entre unas y otras la establece en función de la lengua de origen, la maya. Sin embargo, cuando habla del Estado de Guatemala, utiliza el término de República, pensado en términos liberales ${ }^{28}$.

De ahí que Batres considere que los indígenas como naciones están al margen del Estado y que la única forma de integrarse es a través de la educación, «ese millón de parias que hoy no forman parte de la República, serán en las generaciones próximas otros tanto ciudadanos ${ }^{29}$.

Sin embargo, cuando Valle imagina la nación, lo hace desarrollando un proyecto político más complejo, haciendo hincapié en los elementos unificadores de la época: la educación, las instituciones y las buenas leyes; todo ello para la formación del espíritu público, ámbitos de socialización comunes para todos los grupos. La integración de los distintos elementos que constituyen la nación cívica, se hará por fusión en una cultura, en una lengua y en una raza comunes. Los valores de la homogeneidad frente a la diversidad ya están presentes en este pensador. Posiblemente José Cecilio de Valle haya sido uno de los pocos autores que, desde principios de siglo imaginó un proyecto de nación propia, no sólo guatemalteca, sino centroamericana. En las páginas de El Amigo de la Patria, se comienza a diseñar el plan de nación, a partir de los elementos cívicos, como pueden ser la reordenación territorial, un proyecto económico, una lengua y una cultura comunes.

\section{LA INTEGRACIÓN DEL INDIO A LA NACIÓN: DIFERENCIAS ENTRE VALLE Y BATRES JAÚREGUI}

Para Valle, la integración de los indígenas se llevaría a cabo mediante escuelas elementales, destinadas a promocionar las artes y los oficios. Los agentes sociales del cambio deberían de ser las Sociedades Económicas y las Asociaciones patrióticas de labradores, hacendados, comerciantes y artesanos que deberían contribuir al desarrollo de sus respectivos sectores. También deberían de contribuir los Ayuntamientos, que deberían ser mixtos, integrados por indios, ladinos y españoles, como reza en la Constitución, porque la convivencia diaria y en sociabilidad contribuirá al beneficio común y a la desaparición de las castas.

28 Marta E. CASAUS ARZU, El pensamiento racial y la nación, San José, III Congreso Centroamericano de Historia, 1996. Edgar Barillas, El problema del indio en Guatemala, Guatemala, Escuela de Historia, 1989.

29 El Amigo [25 Coincidimos con Sonia Alda que la política de asimilación del proyecto liberal no diferenció civilización de occidentalización, dado que instruir a los indígenas era sinónimo de asimilarlos a los patrones occidentales, puesto que el ideal del liberalismo era la formación jurídica de una república representativa integrada por ciudadanos responsables. Sonia ALDA, Indígenas y política en Guatemala en el siglo XIX: conflicto y participación en la administración local, Madrid, Universidad Autónoma, 1999. 
Valle aunque hace referencia al indio, como mayoría minorizada, según García, a diferencia de otros pensadores de la época, no lo sublima ni le señala virtudes ni carencias especiales: «No manifestaban talentos los naturales, ni se barruntaba en su descendencia la potencia divina de perfeccionarlos» ${ }^{30}$; tampoco lo denigra como inferior por naturaleza, le reconoce alguna capacidad de conocimiento. Valle subraya el potencial que los indígenas poseen de generar riqueza, debido a su gran capacidad de trabajo: «El indio a quien se ha puesto indolente y perezoso, es activo, capaz de los trabajos más duros... sus manos son las que han hecho esos millones que suponen tan grande trabajo» ${ }^{31}$. No recurre a exaltar la cultura maya en el pasado, como lo hace Batres Jáuregui años más tarde, aunque le concede una relativa importancia al pasado de los Aztecas e Incas. Sin embargo, el imaginario del indio en Batres se acerca más al estereotipo colonial, el indio vago e indolente por naturaleza, semiprimitivo o casi bárbaro, ignorante y salvaje.

A pesar de todo «La historia ... nos demuestra que el indio es susceptible de igual cultura que el ladino» ${ }^{32}$. Partiendo de la idea de que se puede redimir al indio mediante la educación y puede ser ciudadano, plantea que hay medios eficaces para integrar al indio, para que progrese y se civilice, para que adquiera los derechos para vivir en la República. Es necesario hispanizarlos para que salgan de su estado salvaje, obligarles a que abandonen su idioma y vestimenta. Esas medidas son retazos de la Ilustración pero lo novedoso de su propuesta es que considera al ladino el modelo que han de imitar los indígenas y el patrón de asimilación que se ha de seguir. Además, la necesidad de dotar a todos los ciudadanos de instrucción primaria, gratuita y obligatoria, porque «el mundo moderno se ha civilizado merced a su instrucción popular que redunda en su bienestar general». Esta propuesta se completa con el despojo de sus tierras comunales para obligarlos a convertirse en pequeños propietarios, porque a su juicio «la propiedad comunal constituye una de las principales rémoras para el desarrollo».

Coincidimos con Barillas y Alda, en que el elemento central del pensamiento liberal guatemalteco radica en la necesidad de civilizar al indio mediante la asimilación, que no diferencia civilización de occidentalización. Para Alda, se trata de dejar de ser indio para integrarse en una República de ciudadanos occidentalizados. Sin embargo yo considero que el modelo guatemalteco es sui géneris y va más allá de la occidentalización. Plantea un modelo criollo ladino. Criollo por la búsqueda de imitación de patrones occidentales, ladino porque es un proceso gradual de aculturación, que supone dejar de ser indio, perder la identidad étnica para pasar a ser ladino, un concepto ambivalente o ambiguo que se define por su

30 El Amigo [25].

31 El Amigo de la Patria, 20 y 21, Guatemala, 25 de Enero de 1822.

32 Antonio BATRES JAUREGU, Los indios, su historia y civilización Guatemala,, Tipografía Nacional, 1893. En este texto elabora una serie de recomendaciones de corte sarmentiano, bajo el título «Ventajas e inconvenientes de la civilización....Escollos con que tropieza el desarrollo de su civilización. Medio que pueden lograrse para mejorar su avance». 
negación. El «frente ladino «, como llama Taracena al conjunto de criollos, blancos y ladinos, pasó a tener un carácter cultural, al ser concebido, no como mestizaje, sino como un conglomerado no indígena, nada homogéneo y con grandes diferencias económicas, sociales y raciales. Resulta difícil considerar que la homogeneización se dio simplemente por la occidentalización. En el caso de Guatemala, el factor racial jugó un papel determinante en la nueva configuración del Estado y la Nación. Si negamos este elemento, difícilmente comprenderemos la historia social y política de Guatemala y la permanente exclusión del indio del Estado y de la Nación.

Sin embargo, en el proyecto de Valle, las bases de legitimidad sobre las que descansa su imaginario de nación son más incluyentes. El concepto que emplea, de «nacionalizar» o crear una nación de individuos, ilustrados y libres, todos iguales, en cuanto pertenecientes a la misma especie, todos integrados en una sociedad dual, en donde la amalgama fuera la libertad y la propiedad. «La nacionalización» atañe a todos, en ella deben participar todos los grupos sociales, aunque la prioridad la tienen quienes más duramente han sufrido las consecuencias del dominio colonial, los indígenas.

En la medida en que reconoce el trato jurídico de privilegio de los indios durante la Colonia, también reconoce la segregación y exclusión que han padecido sometidos a vasallaje y a tributación. Lo que le parece más grave del período colonial es el aislamiento y segregación que vivieron, lo que no les impidió cultivarse, vivir en sociedad y por ende adquirir la felicidad. Este argumento es muy similar al utilizado por Matías de Córdova para integrar a los indígenas. Otro de los aspectos que le preocupan a Valle es el sistema de castas que dejó la colonia y la heterogeneidad que ello suponía para la formación de ciudadanos libres e iguales ante la ley. «(...)que existiesen los mestisos, que naciesen las castas: que estas se multiplicasen con la introducción de negros y... se formase una población heterogénea, separada en clases, dividida en intereses» ${ }^{33}$. A su juicio este era no de los mayores problemas que enfrentaban las nuevas Repúblicas de América Central.

Por ello y a la usanza del Despotismo Ilustrado y de los arbitristas, aboga por un plan del buen gobierno, un proyecto de inclusión en la nación de las clases desposeídas, para lo cual se debía de efectuar una serie de reformas de las leyes y de las instituciones. Es en este contexto en donde considera indispensable la función de la educación y la creación de las escuelas para gobernar, como una de las mejores formas de integrar a las castas a la ciudadanía y de contribuir a la desaparición de la diversidad.

En contra de la opinión de Palmer, Batres está muy influenciado por el positivismo y el pensamiento racial de la época. Sin llegar a afirmar la inferioridad genética de los indígenas, los considera inferiores en civilización y cultura. Lo

33 Rafael Heliodoro DEL VAlle, Pensamiento vivo de José Cecilio del Valle, Costa Rica, Educa, 1971, p. 215.

R. I., $1999, \mathrm{n}^{\circ} 217$ 
que tienen en común ambos autores es considerar la educación como el principal vehículo de integración en la nación y, en ese sentido, podemos afirmar que poseen un proyecto homogeneizador; ambos desean la formación de buenos ciudadanos, pero los medios y modelos sugeridos, así como los principales agentes del cambio difieren en uno y otro pensador.

\section{LA EDUCACIÓN PARA LA CREACIÓN DE CIUDADANOS LIBRES Y FELICES EN VALLE.}

Para García, el proceso de educar al pueblo no es complicado para Valle, aunque sí largo. Basta adoptar otras experiencias, porque la reacción de los educandos será la misma «se ilustra a un pueblo como se ha ilustrado otro pueblo: se civiliza una nación como se ha civilizado otra nación. Esta es la resolución del problema» ${ }^{34}$. Este proceso de «nacionalizar» es gradual, consiste en integrar educando al «espíritu público», fomentando los conocimientos de cada una de las categorías sociales, a través de la prensa, cuyo papel en este sentido es muy importante ${ }^{35}$. Sirve para formar ciudadanos útiles a la República, idea omnipresente en la obra de Valle.

El otro elemento fundamental para la formación de buenos ciudadanos, a juicio de García, es el trabajo, «No hay proceso unificador que no contemple el trabajo como el elemento motor y unificador de los componentes de la sociedad. Desempeñado por cada una de las categorías de modo correcto, se construye la patria. Es necesaria la participación activa de todas las clases: los sabios, los capitalistas y los operarios; se trata de integrar en la nación también a los propietarios, respetando y garantizando su propiedad, educándolos en el espíritu público» ${ }^{36}$.

Para Valle, la integración del indio por medio de la educación, posee muchas similitudes con el pensamiento ilustrado y en definitiva supone un proceso de hispanización. Consiste en tomar distintas medidas: de carácter lingüístico, porque se confía indiscutiblemente en la fuerza homogeneizadora del castellano, como principal vehículo de asimilación de los indígenas a la nación. «El indio después de tres siglos no sabe hablar el idioma de Castilla por dos razones: $1^{\text {a }}$ Porque la ley le ha alejado de los que podían enseñársela; $2^{a}$ Porque no ha tenido

34 Teresa GaRCIA GIRALDEZ, El proyecto de nación y la visión del indio en el pensamiento político de Valle y Batres Jáuregui, San José, Costa Rica, III Congreso Centroamericano de Historia, 1996. El Amigo de la Patria, Guatemala, 5 de Julio de 1821.

35 Valle propone la creación de «un periódico que, dividido en partes, presentase: a los eclesiásticos, el modelo de los que han sido más patriotas; a los aristócratas, el ejemplo de los que han hecho servicios más distinguidos; a las mujeres el de las más ilustradas; y al pueblo, los principios de Derecho Constitucional, la necesidad de la instrucción elemental, etc.»; porque, «Las fuentes de donde los hombres derivan las riquezas son: La enseñanza, el sacerdocio, el comercio, la industria y la agricultura.» DEL VALLE [33], pp. 105 y 106.

36 Garcia GiraldeZ [19]

\section{R. I., 1999, n. $^{\circ} 217$}


confianza de los ladinos, y cuando no hay confianza se inventa o conserva una lengua que haga impenetrable la expresión de sentimientos ${ }^{37}$.

Valle propone diferentes estrategias para llevar adelante la educación de los indígenas, desde una óptica más integradora que asimilacionista, que van: desde que se aprovechen los viajes de los diputados centroamericanos para participar en las Cortes españolas y se haga una selección y lleven a España, hasta que se tomen «medidas suaves; pero eficaces para que los indios vayan vistiendo à la Española según sus facultades respectivas» ${ }^{38}$. Aquí hay de nuevo un retorno a las propuestas de Matías de Córdova y de la Sociedad Económica de Amigos del País.

Vuelve a retomar la propuesta de Tomás López de fomentar los matrimonios mixtos para conseguir una mejor armonía en la nueva sociedad y propone el fomento de cruces interraciales entre indios y ladinos, pero también entre españoles y centroeuropeos. La inclusión mediante la fusión de las castas, como sinónimo de civilización. Este proceso será más efectivo cuanto más se fomenten los matrimonios mixtos «con individuos de otras clases para que vayan desapareciendo las castas y haya unión en nuestra población ${ }^{39}$. Con ello se producirá una transformación física y moral de las castas y sobre todo de los indígenas que mejorarán sus condiciones físicas y tranformarán su carácter.

Para Valle son varios los agentes del cambio, los párrocos, los filósofos y los sabios como grupo impulsor, pero sin duda es el Estado y especialmente los ayuntamientos y las instituciones encargadas de poner en marcha todo el proceso de hispanización, pero con el apoyo de la sociedad, de los otros grupos sociales, no importa su status étnico o de riqueza, los llamados a realizar el proceso de cambio y aculturación, porque para Valle, contrariamente a otros pensadores de su época, lo que está en juego es un proyecto de nación integradora, en el cual deben estar involucrados todos y cada uno de los ciudadanos que habiten el territorio de América Central.

La influencia de Jose Cecilio del Valle será enorme en la legislación de la época, fue el redactor del Acta de lndependencia y se cree que uno de los redactores de la Constitución de 1824. Gran parte de sus ideas fueron recogidas en la legislación posterior y han permeado todo el ideario de la Federación y de los

37 El Amigo de la Patria,, 16 de octubre de 1820.

38 El Amigo[25] Es curioso ver cómo, desde que empiezan los concursos sobre el tema de "contribuir al mejor sistema para que los indios vistan y calcen a la española», a finales del siglo XVIII, se produce un cambio: un siglo más tarde como deben vestir y calzar es «a la ladina».

39 Considero que en esta cita de Valle, como en muchas otras existen precedentes del proyecto eugenésico, dado que se hace referencia al cruzamiento de indígenas y ladinos con españoles, suizos y alemanes y se considera que ello mejorará las condiciones físicas y psíquicas de la población guatemalteca, «Se mudarán las fisonomías y tallas, las organizaciones y caracteres. Esos americanos tristes y desmedrados que solo hablan 'ayes' y 'suspiros', se tornarán hombres alegres, altos y hermosos como los sentimientos que darán vida a su ser. No serán humildes como los esclavos: Tendrán la fisonomía noble del hombre libre». El Amigo [25] 
partidos unionistas posteriores, en cuyos programas aún se deja sentir la influencia de Valle ${ }^{40}$.

\section{LA EDUCACIÓN COMO ELEMENTO CIVILIZADOR Y VEHÍCULO DE ADQUISICIÓN DE CIUDADANÍA EN BATRES JAÚREGUI}

La influencia positivista va a estar muy clara en Batres y en su concepción de la educación de los indígenas. Su idea de civilizarlos en las escuelas, para conseguir su desarrollo y progreso, resulta evidente en toda su obra. El modelo de asimilación o integración varía poniéndose el énfasis en la civilización u occidentalización del indio, justificando las medidas que se tomen debido a la inferioridad de su raza, su cultura o la valorización negativa de ciertos rasgos culturales. La vía para alcanzar esa meta es la ladinización.

A partir de entonces la ladinización aparece como sinónimo de civilización, progreso y ciudadanía, convirtiéndose en el discurso hegemónico más generalizado a la hora de pensar en la nación y en la integración del indio ${ }^{41}$.

Distintos de los de Valle son los fundamentos de su diseño «civilizador». Se basan sobre todo en la incorporación del indio a la República a través de su conversión en pequeño propietario y buen agricultor, pero para ello es menester que adquiera todas las virtudes, costumbres y cultura de los ladinos y que aprendan a ser pequeños empresarios» ${ }^{42}$.

El proyecto en materia de educación que Batres propone no está alejado del modelo de otros positivistas de su época y posee una clara influencia comtiana. Propone un plan global de educación mediante la fundación de Institutos Nacio-

40 Garcia Giraldez,[19].Rodriguez BeteTa [19]. Jorge SkinNER KL EE, Legislación indigenista en Guatemala, México, Instituto Indigenista Interamericano, 1954 y Revolución y derecho. Una investigación sobre el problema de la revolución en el derecho guatemalteco, Guatemala, Seminario de Integración Social Guatemalteca, 1971.

41 Como opina Alda la valorización en el proyecto liberal tendió a perfilar la idea de una democracia compuesta por ciudadanos alfabetizados; mediante la exclusión de los analfabetos a votar y a ser votados se restringió de la ciudadanía a la mayor parte de la población indígena. Este proceso se inicia en 1840 y se completa con la constitución de 1920. ALDA, [28].

42 «Si el deseo de poseer, si el aliciente de ser propietarios, si lo tuyo y lo mío encierran en todos los países y en todas las razas uno de los principales incentivos de progreso, en la raza indígena tal vez sea el único. Proporciónesele la manera de adquirir la propiedad». Antonio BATRES JAUREGUI, Dictamen y conclusiones que la comisión respectiva presentó al Congreso Pedagógico sobre el tema siguiente: "¿Cuál será el medio más eficaz para civilizar á la raza indígena en el sentido de inculcarle ideas de progreso y hábitos de pueblos cultos?», Guatemala, Tipografía El Comercio, 1894. Uno de los idearios de los liberales va a ser el impulso de una sociedad de individuos jurídicamente iguales, basada en la propiedad individual ; de ahí que el pequeño propietario rural sea idealizado. R. WILliams, States and social evolution, coffee and rise of national governments in Central America, University of North Carolina Press, 1994; así como W. RosEBERRY et all., Coffee, society and power in Latin America, John Hopkins University Press, 1995.

R. I., 1999, $\mathrm{n}^{\circ} 217$ 
nales de indígenas y la creación de Escuelas Agrícolas para Indígenas, contempladas en el Dictamen, que después tuvo su reflejo en las constituciones de 1879 y 1920 y en la legislación de la época de la cual él fue uno de sus principales impulsores ${ }^{43}$.

En el Dictamen, la Comisión Pedagógica elabora cuarenta y cuatro propuestas, divididas en cuatro epígrafes: Educación, Instrucción, Protección de indios y Tratamiento de los idiomas, trajes y costumbres, aprobadas por el Congreso durante el mandato del General José María Reina Barrios, que se plasmaron en el decreto de 20 de octubre de 1893, creando el primer Instituto Nacional Central para Indígenas y en el Acuerdo Gubernativo del 20 de enero de 1894, que establecía el reglamento del Instituto Agrícola. El objetivo básico era «mejorar la condición de la clase indígena» y conseguir que «el indio avance en civilización».

En estas instituciones se establece un plan de estudios de clara influencia positivista, combinando materias de carácter general, como geografía, historia, matemáticas y lengua castellana, con clases prácticas, «con el fin de fomentar el espíritu de observación y la adquisición de experiencias en el campo». La complementariedad de conocimientos científicos y prácticos, y la inclusión de materias de carácter ético y de urbanidad para la formación de buenos ciudadanos, constituyen el pensum de cuatro años que duraba la instrucción ${ }^{44}$.

Este proyecto general de educación media, inspirado por Batres Jáuregui y convertido en leyes durante varios gobiernos liberales ${ }^{45}$, representa el intento más serio e integral de llevar a cabo un proceso de homogeneización e integración del indio en la civilización por medio de la educación. Sólo de esta manera, opinaba Batres, podría el indio civilizarse y equipararse a la clase superior de los ladinos.

A partir de entonces el modelo guatemalteco pasará por la ladinización de los indios, por la asunción de los valores, pautas culturales y de comportamiento de todos aquellos grupos que asumían el modelo occidental. Aculturación y ladinización van a ser dos caras de la ciudadanía del siglo XX y de la incorporación al Estado. El proceso de integración ya no pasará exclusivamente a través de la hispanización, de los autores anteriores, sino que la ladinización se convierte en el único medio para adquirir la ciudadanía.

43 SKINNER KLEE [40].

44 El concepto de ciudadano moral como padre de familia, propietario y de una moralidad intachable, se vinculaba a los valores de la civilización occidental. La inclusión de asignaturas de ética y moral en el programa de estudios tenía como finalidad la formación de ciudadanos cívicos y responsables. Sobre estos temas de educación y ciudadanía en América Latina, Antonio ANNINO y Raymond Buve, El liberalismo en México, Munster-Hamburgo, Ahila, 1993. Charles Hale, The transformation of liberalism in nineteenth century Mexico, New Jersey, Princeton University Press, 1989.

45 De 1879 a 1920, se dictaron más de 10 Acuerdos gubernativos y se emitieron una serie de decretos estableciendo Liceos, Escuelas e Institutos para indígenas. Acuerdo Gubernativo de 6 de septiembre de 1879,9 de febrero de 1880,4 de enero de 1881 , estableciendo un liceo para niñas indígenas en Cobán, los ya mencionados de 1893 y 94, hasta el 24 de diciembre de 1920, estableciendo una Escuela normal de indígenas. 
Su idea de ladinización se expresa en los siguienes términos: «Las manifestaciones exteriores de la cultura del hombre y las diferencias especiales que lo distinguen del no civilizado, no son otras que el traje, los hábitos y costumbres $\mathrm{y}$, finalmente el idioma. Así el indígena que habla el castellano, que viste á la europea, ya no le llamamos indio, ya no lo distinguimos de la raza mistada; y si además tiene los hábitos y costumbres de los ladinos, es tan culto como ellos, y con ellos se asimila, se mezcla y se confunde». Esta concepción va a permear todo el discurso hegemónico y va a legitimar y a fundamentar la mayor parte de las medidas integracionistas de fin de siglo y principios del siglo $\mathrm{XX}^{46}$.

El principal vehículo para esta homegeinización social y cultural va a ser el Estado a través de leyes, acuerdos gubernativos, censos, hasta tal punto de llegar a convertir a algunos pueblos indígenas por decreto gubernativo en ladinos ${ }^{47}$. Como opina Taracena, el Estado liberal buscó la homogeneización de la población por vía de la ciudadanía, convirtiendo por decreto el Estado tripolar, en materia étnico cultural, compuesto por criollos, ladinos e indios, en un Estado bipolar, compuesto solamente por ladinos e indios. A los indígenas que no se ladinizaran, se les aplicó una política de segregación y exclusión política restringiéndosles los derechos de ciudadanía ${ }^{48}$.

EL FRACASO DEL PROYECTO LIBERAL LADINO, LA BÚSQUEDA DE NUEVOS IMAGINARIOS DE NACIÓN Y DE INTEGRACIÓN DE LA POBLACION INDÍGENA A LA NACIÓN.

Con el inicio del siglo XX y en gran parte debido a la férrea dictadura de Estrada Cabrera (1898-1920), se genera un fuerte movimiento social y político urbano, que se conforma para derrocar a la dictadura ${ }^{49}$. Este movimiento va a estar

46 Si comparamos el concepto de ladinización en Batres con el que Richard ADAMS y gran parte de la antropología cultural norteamericana acuñan a partir de 1950, veremos que las similitudes son enormes. CASAus ARZu, [28].Carlos GuZMAN Bockler, Colonialismo y revolución, México Siglo XXI, 1975.

47 Justo Rufino Barrios, por decreto del 13 de octubre de 1876, con el fin de mejorar la condición de los indígenas de ambos sexos del Pueblo de San Pedro Sacatepéquez, los declara ladinos y les prohibe la utilización del idioma y de sus trajes. Medidas de este tipo se han de tomar varias a lo largo del siglo XIX y XX.

48 Arturo TARACENA ARRIOLA, «Guatemala y sus retos desde la óptica de un historiador político», mimeografiado para el seminario de Visión Guatemala, 1999. Así como su libro, Invención criolla, sueño ladino, pesadilla indígena. Los Altos de Guatemala, de región a Estado, La Antigua Guatemala, CIRMA, San José. Porvenir, 1997. El proceso de restricción de la ciudadanía va a ser gradual a partir de mediados del siglo XIX, especialmente de la ley electoral de 1851. Las diversas justificaciones de «civilizar al indígena o de ladinizarlo» supusieron fórmulas de exclusión de la población indígena como elector y como ciudadano. CASAUS ARZU [28] y ALDA[29].

49 Sobre este tema las revistas Studium; Revista de Educación popular. H. ProwE, «El indio», I, 3, julio, 1903, pp. 42-45. Revista del Trabajo, julio, 1925 pp. 349-352, «Por el indio», así 
conformado por la mayor parte de las elites intelectuales y políticas del período que participan en una crítica y fecunda polémica que se establece en las universidades, en el congreso de la República, los clubs, asociaciones y medios de comunicación del país en torno a 1920, abriendo un nuevo horizonte intelectual en donde se debaten nuevas temáticas o se ponen sobre el tapete viejos tema con diferente enfoque. Durante este periodo aparece nuevas revistas y periódicos en los que escriben los principales intelectuales del país, con un intercambio muy fructífero con otros países de América Latina. Se retorna a la discusión sobre el unionismo y el centroamericanismo, se reflexiona sobre la nación y el «problema del indio»; la educación y la ciudadanía continúan siendo temas recurrentes y se abren nuevas polémicas como la emancipación de la mujer, la regeneración de la sociedad y los valores de la justicia, el derecho y la soberanía ${ }^{50}$.

Este espacio de debate generacional se mantuvo abierto durante más de dos décadas, hasta la revolución de 1944, y los componentes de la generación se caracterizan por los siguientes rasgos:

a) Es una generación que surge en el contexto histórico de dos dictaduras y cuya meta aparece asociada a lucha por su derrocamiento y a la regeneración de la patria con los ideales del unionismo centroamericano.

b) Su composición étnica es totalmente ladina y básicamente capitalina y la extracción social de sus miembros es variada, aunque parecen predominar las clases medias urbanas y miembros destacados de las elites familiares de la oligarquía.

como todo el debate que se genera en el Diario de Centroamérica y en El Imparcial sobre la mejora de la raza del indio. Brañas en sus artículos en El Imparcial opina que el problema étnico se complica con la multiplicación del ladino degenerado, procedente del indio mestizado con razas pobres. Es uno de los partidarios de la inmigración selectiva de los europeos para mejorar la raza. El Imparcial, 16 de enero de 1930.

49 Sobre la dictadura de Estrada Cabrera cabe mencionar excelentes trabajos de autores de la Generación del 20 como Carlos WYLD OSPINA, El autócrata, ensayo político social, Guatemala, Tipografía Sánchez y de Guise, 1929. Dibuja un excelente retrato del dictador. Rafael AREVALO MARTINEZ, Ecce Pericles, historia de la tiranía de Manuel Estrada Cabrera, Guatemala, Tipografía Nacional, 1945 o la excelente novela de Miguel Angel ASTURIAS, El Señor presidente, Madrid, Aguilar, 1969.

50 Son varias las revistas y periódicos de la época que abordan estos temas. De la selección estudiada por nosotros para nuestra investigación cabe señalar por fecha de aparición, Electra, 1920, Studium, 1921-1942,Vida,1925-1940, Tiempos Nuevos, 1929, Todas ellas vinculadas a la Universidad de San Carlos y dirigidas por miembros de la Generación de 1920. Los diarios revisados de la época han sido, El Imparcial, Diario de Centroamérica, Tiempo, Nuestro Diario, La Gaceta. Así como otras revistas más especializadas, como Revista del Trabajo, Revista de la Educación de la Policía. En todas ellas el tema de los problemas raciales, la redención del indio y su instrucción aparecen constantemente. Sobre esta generación hay muy pocos estudios, cabe destacar el de Epaminondas QuintanA, La Historia de la Generación de 1920, Guatemala, Tipografía Nacional, 1971. 
c) El mayor rasgo de unidad en todos ellos es el haber estudiado la secundaria en el mismo centro, El Instituto Nacional Central para Varones, haber participado en las Huelgas de Dolores y haberse opuesto a la dictadura de Estrada Cabrera ${ }^{51}$.

d) Ideológicamente son claros herederos del liberalismo decimonónico y el positivismo spenceriano, en la exaltación de valores como la libertad frente a la igualdad, el culto a la razón frente a la religión, su afán por el progreso y creencia ilimitada en la ciencia, su culto a los intelectuales y a la cultura como factores de modernización, la educación como remedio de todos los males, su fe en el evolucionismo social spenceriano, en donde la raza se convertía en una de las preocupaciones centrales de su pensamiento ${ }^{52}$.

e) Estuvieron muy influidos por las teorías raciales en boga en Europa y en América Latina. Por sus escritos y por la reproducción de los artículos de pensadores como Le Bon, Ingenieros, Bunge, Taine, deducimos que conocían bien el pensamiento de estos autores y trataban de adaptarlo a la realidad social guatemalteca y centroamericana.

f) Es patente, en gran parte de la narrativa del grupo, un afán regeneracionista y una exaltación a la patria, la libertad y los valores ciudadanos como ejes fundamentales para la formación de la nacionalidad centroamericana y de las repúblicas en particular. Por influencia de José Cecilio del Valle, distinguían entre patria grande, centroamericana y la patria chica, la unidad territorial y política construida por la nación guatemalteca ${ }^{53}$.

No parece haber consenso en ellos sobre el modelo de nación o qué tipo de nacionalidad, en los términos de la época se va a adoptar en Guatemala. Tampoco existe una idea clara en ellos sobre lo que entienden por nación homogénea. La mayor parte de ellos se refieren a una nación racialmente homogénea, no por

51 José BARNOYA, «Los doscientos pechos y cuatrocientas nalgas». Carlos GUZMAN BoCKLER, «La Huelga de Dolores que viví con mi generación», en Revista de la USAC, Guatemala, USAC, $\mathrm{n}$. 1 y $2,1998$.

52 Sobre los principios rectores del liberalismo decimonónico y la influencia del positivismo, Charles HALE, «Las ideas políticas y sociales en América Latina 1870-1930» en Leslie BETHELL, Historia de América Latina, vol. 8. Cambridge University Press, 1991 (versión española, Barcelona Crítica, 1991). Así como Charles HALE, El liberalismo mexicano en la época de Mora, 1821-1853, México, Siglo XXI, 1972. Monica QUIJADA, «En torno al pensamiento racial en Hispanoamérica: una reflexión historiográfica», en Estudios Interdisciplinarios de América Latina y el Caribe, vol. 3, enero-junio, 1992, pp.: 110-129.

53 Resulta interesante cómo Quintana, haciendo una reflexión sobre cuál era el credo de esta generación, opina : «Amor a la patria, amor por la cultura y la instrucción, patriotismo guatemalteco y amor por la unidad de Centroamérica», constituyen los ideales de la generación del 20. QuintanA, [50] p.372 y sigs. Por nación está entendiendo «La unidad de ciudadanos de buena fe capaces de forjar una patria nueva en donde el indio tenga cabida en el futuro». 
la vía del mestizaje sino por la vía del blanqueamiento racial o del exterminio de la raza indígena.

Muchos de ellos escriben artículos acerca de la población indígena, pero son escasos aquellos que valorizan la cultura autóctona como elementos positivos de configuración de un imaginario nacional. El tema está ausente en sus primeras publicaciones, y cuando escriben, lo hacen como problema u obstáculo para el progreso de la nación.

Fue una generación heterogénea y llena de contradicciones políticas e ideológicas, pensamos que a causa de su extracción social y de sus intereses económicos muy dispares. Se dispersa pronto, en cuanto cae la dictadura de Estrada Cabrera, se divide durante el régimen de Ubico, por el apoyo de algunos de sus miembros. Vuelve a bifurcarse con la revolución de 1944, constituyéndose dos rumbos muy diferenciados. Aquellos que apoyaron a la década revolucionaria y se mantuvieron firmes y en oposición durante la contrarrevolución y los que a partir de 1963, dieron su apoyo o consentimiento a los regímenes militares.

Lo que no cabe duda es que de esta generación salió un buen número de elites intelectuales en el campo de la ciencia, la política, la sociología y la literatura, que posteriormente influirían en muchos espacios de la sociedad y de la política de Guatemala y Centroamérica y contribuyeron a crear un modelo sui generis·de exclusión de la población indígena a lo largo del siglo $\mathrm{XX}$, que luego ha tenido graves consecuencias para el desarrollo posterior de la nación y del Estado.

\section{LA INVIABILIDAD DE LA NACIÓN POR LA DEGENERACIÓN DEL INDIO Y DEL MESTIZO.}

En varios autores de esta época y algunos de la generación de 1898, existe un sentimiento de pesimismo ante el fracaso de las reformas liberales en su afán de integrar al indio mediante la educación y la civilización. Son innumerables los artículos de prensa lamentándose de los escasos resultados del proyecto de Batres sobre las Escuelas Agrícolas, proponiendo nuevas medidas y métodos para redimir al indio e «incorporarle a la civilización» ${ }^{54}$.

La principal razón aducida para el fracaso del proyecto liberal, es que la población indígena es una raza degradada o degenerada, incapaz de civilizarse o redimirse por medio de la educación. Pero no sólo el indio padece esta suerte, sino el mestizo se encuentra en una situación de mayor inferioridad que el indio,

54 El debate sobre el fracaso de las reformas liberales en materia de educación y civilización del indio se da en dos periódicos, El Diario de Centroamérica y Orientación social, 1 de septiembre, 1928. En El Diario de Centroamérica aparecen artículos en esa dirección, el 26 de mayo 1902, el 3 y 10 de mayo de 1911, 19 de julio de 1919, 10 de mayo de 1920, entre los más destacados. 
porque se mezcló con una raza impura, la española, y el cruzamiento de sangres provocó una degeneración irreversible ${ }^{55}$.

Resulta interesante resaltar los concursos mensuales, científico literarios de todas las revistas mencionadas con temas como las luchas raciales, la eugenesia y los males de Centroamérica, la raza. Los trabajos premiados recibían premios importantes y sus trabajos eran publicados. Casi todos ellos tienen como punto de referencia a dos pensadores, Jose Ingenieros y Octavio Bunge ${ }^{56}$.

Son varios autores los que abordan el tema de la degeneración genética de las razas como un hecho irreversible, tanto para el indio como para el mestizo. El énfasis hay que buscarlo en aquellos que piensan que es una cuestión genética e innatista y por ende no pueden ser redimibles y no se les puede regenerar, como es el caso de Miguel Angel Asturias, Horacio Altamirano o Samayoa Chinchilla y aquellos que consideran que la degeneración fatal sólo afectó a los mestizos y que los indígenas en la medida en que procedían del «pueblo ario», en un pasado remoto, fue la mezcla con los españoles y otras razas lo que provocó su decadencia ${ }^{57}$.

A pesar de que esta última narrativa es cuantitativamente menor en el discurso de la época, sí supone una nueva vertiente en el pensamiento social guatemalteco. Conviene resaltar que para ninguno de estos autores el patrón o modelo es la ladinización y mucho menos el mestizaje, ya que para ambas corrientes, el mestizo es una raza más degenerada que el indio.

Analicemos a tres de los autores más representativos: Miguel Angel Asturias, enormemente influido por el positivismo en su vertiente spenceriana, por las teorias racialistas, y especialmente por el determinismo genético; Horacio Espinosa Altamirano, influido por el determinismo psicológico y etnoambientalista, más vinculado intelectualmente a Taine e Ingenieros y Fernando Juárez Muñoz, en el que nos detendremos más por la complejidad y riqueza de su pensamiento

\footnotetext{
55 En la línea de la degeneración de la especie y las taras de los indígenas, con un planteamiento propio de las teorías raciales de la época, nos encontramos El Imparcial, en varios editoriales, 16 de septiembre, 1922, Revista de la policía, 11 de noviembre,1928, pp :1731 y sigs., La Gaceta, 11 de noviembre, 1928 .

56 Sobre estos temas véase, «La razón básica de los males de Centroamérica en, Studium, n.14, pp. 71-75, septiembre-octubre 1923, «Problemas raciales» y «el Jardín de la eugenesia» pp. 59-62 ; Studium, un.12, junio-julio 1923,. En la sección «Latinoamerianismos», son numerosos los artículos de José Ingenieros, Carlos Octavio Bunge y Gustave Le Bon, en menor número de ocasiones aparece José Vasconcelos.

57 Otro autor de la época que aborda este tema fue Rafael Arévalo Martínez que inspirado en Bunge opina que la degeneración viene provocada por la influencia del trópico, la alimentación deficiente, el desenfrenado apetito sexual y el alcoholismo. Véase Ramón GonZaLEZ PonCIANO, «Esas sangres no están limpias: modernidad y pensamiento civilizatorio en Guatemala 1954-1997», en Clara ARENAS et all, Racismo e Identidades en Guatemala, Guatemala, Avancso, 1997. Este autor confirma que para la época estudiada, tanto indígenas como ladinos eran razas degeneradas y no estaban preparadas para ejercer sus derechos civiles.
}

R. I., 1999, $\mathrm{n}^{\circ} 217$ 
Lo que resulta evidente es que aquellos para quienes la raza indígena es una raza inferior genéticamente, incapaz de regenerarse, consideran que la solución va a ser la eugenesia o el exterminio. Para los que la degeneración es más psicológica o ambiental, producto de un cruzamiento desgraciado o de un desequilibrio racial nefasto, fruto del choque violento entre españoles e indios, las posibilidades de redención y regeneración son escasas, pero se pueden producir por medio del trabajo, la educación o, en el mejor de los casos la incorporación plena a la ciudadanía.

Asturias interpreta la degeneración de la raza indígena desde la óptica de las teorías racialistas, especialmente al considerar que el nacimiento y muerte de una civilización viene provocada desde el momento en que se inicia la hibridación, no porque ésta sea negativa en sí misma, sino por el hecho de que ésta provoca adulteración de la raza y alteración de las sangres, lo que indudablemente conlleva la decadencia de la civilización ${ }^{58}$. Como bien dirían estos autores, la degeneración de una nación se produce por el cruzamiento de sangre, como resultado de esta atracción fatal, fruto de esta confusión racial se produce el atraso y la inferioridad de las razas y de algunos pueblos como el africano, americano o asiático.

Asturias se pregunta si los indígenas mejoran o se degeneran con el tiempo y llega a la conclusión por sus estudios fisiológicos, anatómicos y psicológicos, que,«En rigor de verdad, el indio psíquicamente reúne signos indudables de degeneración; es fanático, toxicómano y cruel», por lo que «resulta evidente la decadencia de la raza indígena» ${ }^{59}$. Entre las múltiples causas que enumera, la mayor parte de ellas son de índole económico y social, la mala alimentación, la falta de higiene, el excesivo trabajo, el casamiento prematuro, las enfermedades, el alcoholismo y ya apunta al punto central que va a ser el núcleo central de su tesis: la falta de cruzamiento ${ }^{60}$.

Asturias, influido por Le Bon, parte del supuesto de que el indígena es una raza estancada, porque la fusión de su sangre está agotada y de ahí procede su

58 Para Gobineau como para Asturias y Muñoz existe una estrecha relación entre raza y civilización, para ambos las razas no vienen determinadas por el medio ambiente o por el clima como pensaría Espinosa Altamirano, sino por la mezcla de sangres. «Los pueblos no se degeneran mas que a consecuencia y en proporción a las mezclas que sufren»...» La vida de una raza esta hecha de una serie infinita de mezclas, y, por ende, de mancillas». p.164. Lo mismo piensa nuestro autor. Todor Todorov, Nosotros y los Otros, México, Siglo XXI, 1991. Resulta muy novedoso el libro de Robert Young, Colonial Desire, hibridity, culture and race, Londres, Routledge, 1995.

59 Miguel Angel Asturias, «El problema social del indio», Tipografía Sánchez y de Guise, Guatemala, 1923.

60 AstuRIAS [ 59], p. 47 Una de sus frases más comentadas en su tesis: «Hágase con el indio lo que con otras especies animales cuando se presentan síntomas de degeneración.....porque no se traen elementos de otra raza vigorosa y mas apta para mejorar a nuestros indios». Siguiendo la línea de Taine, Le Bon e Ingenieros opina que «Los indios se han gastado ellos mismos, su sangre no ha hecho a través de incontables generaciones, sino girar en un círculo...Hace falta sangre nueva, corrientes renovadoras que resarzan la fatiga de sus sistemas, vida que bulla pujante y armoniosa». p. 52. 
degeneración; pero va más allá que Juárez Muñoz al afirmar que esa degeneración no es fruto de la historia, ni del cruce con los españoles, sino del cruzamiento entre ellos mismos, que es lo que ha producido su decadencia, como dirían Renan o Gobineau. Es la fusión de sangre mezclada lo que ha producido la decadencia de la civilización y la emergencia de una raza inferior, porque procede de una civilización primitiva o atrasada. Para Asturias los rasgos psicológicos no son más que expresión de sus rasgos físicos, propios de las razas inferiores.

En su descripción de la civilización indígena, considera que, «El indio no pudo, ni ha podido, ni podrá incorporarse de un golpe a la cultura avanzada que tiene la minoría», puesto que se ha producido una degeneración permanente de la raza indígena, lo que le impide acceder al progreso y a la civilización moderna» ${ }^{61}$.

Para Espinosa Altamirano, la inferioridad de la raza hispanoamericana se debió al cruce entre españoles e indígenas y lamenta que este cruce no se haya producido con anglosajones. Siguiendo las tesis de José Ingenieros considera que el desequilibrio étnico se produjo por el choque violento entre indígenas y blancos. $\mathrm{La}$ inferioridad proviene «por ser hijos de una violenta unión de dos razas psicológicamente antagónicas llevando con ello al desequilbrio étnico correspondiente ${ }^{62}$.

Fernando Juárez Muñoz es una autor que está a caballo entre los dos siglos, muy influido por el positivismo y las teorías raciales durante la primera etapa de su vida y posteriormente da un giro en su pensamiento adaptando las ideas de los pensadores mexicanos que hemos denominado las teorías de la mestizofilia ${ }^{63}$.

Para Juárez Muñoz, el problema de la «raza india» y sus causas de inferioridad vienen provocados por el cruce nefasto con otros pueblos, especialmente el español y por la privación de libertad y la sumisión a la que se vio sometido con la conquista y colonización. Para este autor, como para muchos otros de su época, la causa de los males de la nación y del indio se encuentran en «este cruce inevitable....formó otra clase de criollos, mezcla de españoles un tanto degenera-

61 Este mismo concepto es utilizado por Manuel Gamio en su artículo sobre el mestizaje eugenésico en la América Indo-Ibérica, en Anales de la Sociedad de Geografía e Historia de Guatemala, Tomo V, n. 3, marzo, pp. 333-337. Gamio considera que existe una dicotomía entre la civilización moderna y la raza blanca y la mayoría de raza indígena y la civilización atrasada. De la misma manera M.A Asturias vincula la civilización moderna a los mestizos o ladinos y la atrasada a la población indígena. Esta dicotomía se va a generalizar a toda la ciencia social guatemalteca a través del Seminario de Integración Social Guatemalteco. Véase ASTURIAS [ 51],p. 74 y sigs.

62 Véase Horacio ESPINOSA AltamiRANo, El libro del buen ciudadano, Guatemala, Tipografía nacional 1930.p. 10 y sigs. Así como su artículo premiado en la revista Studium,n. 12, 1923, «Problemas raciales», en la que respondiendo a los argumentos de Ingenieros, expone «por qué los hispanoamericanos intertropicales somos incapaces de construir una nación culta y civilizada». pp: 59-61.

63 Fernando JUAREZ MUÑOZ no perteneció a la generación del 20, es contemporáneo de Batres Jaúregui. Escribe varios libros acerca de los problemas sociales del país, sobre la necesidad de formar una nación y la situación del Indio. Entre su obra sociológica cabe mencionar, Nuestros problemas, apuntes del Ambiente, Guatemala, Sociedad de Geografía e Historia, 1926. El indio guatemalteco, ensayo de sociología nacionalista, Guatemala, Tipografía Nacional, 1931. $1^{\text {a }}$ edición y $2^{\mathrm{a}}$ edición en 1946.

R. I., $1999, \mathrm{n}^{\circ} 217$ 
dos....y la raza aborigen, pura.... «esto fue lo que produjo la herencia de una raza viciosa y haragana» ${ }^{64}$.

Este determinismo biológico se refleja de forma especial en el capítulo titulado «La condición moral y psicológica del indio» en donde expresa claramente la influencia del determinismo moral y racial. Es el mestizaje, fruto de la fusión de razas degeneradas lo que ha producido una tipología del carácter y de la personalidad india, en otros términos un estereotipo, el cual se hace muy difícil cambiar. Por ello el indio es por naturaleza: haragán, huraño, desconfiado, perezoso, vicioso y vengativo. Y retorna de nuevo a su anterior argumento opinando que, «la principal causa ha sido la mezcla ingrata de sangre india y la española que dio vida a lo que se pudiera llamar raza americana: el mestizo con todas las indolencias, todas las molicies y todas las pasividades de ambos elementos del cruce» ${ }^{65}$.

Sin embargo, Miguel Angel Asturias parece estar más influido por Le Bon y Renan y por autores latinoamericanos de la época como Manuel Gamio, Octavio Bunge y José Ingenieros. Asturias, en el capítulo sobre, sociogranología, considera que la fisonomía del indio, «es de suyo fea, la nariz y la boca anchas, los labios gruesos, las comisuras hacia abajo, los pómulos salientes, el ojo oblicuo amortiguado» ${ }^{66}$.

Aquí podemos observar la influencia de todas las corrientes del determinismo integral que van desde Voltaire, Bufforn y Taine hasta las ultimas corrientes innatistas del siglo XX. El hecho de que a unas condiciones físicas determinadas vayan inevitablemente aparejadas condiciones morales y mentales ya es un pensamiento común en el siglo XVIII y se refuerza con intelectuales como Renan, Taine y le Bon, para los que las condiciones morales del individuo están predeterminadas por lo biológico y racial, por ello es integral, y nada se puede hacer para cambiar esa ley general. De ahí parte el principio de la irreversibilidad de la condición humana y de la imposibilidad del progreso o perfectibilidad del ser humano.

Resulta interesante observar que, durante el período estudiado, el ladino no aparece como patrón cultural a imitar, más bien parece que se recalca la oposición o el binomio entre indios y ladinos. El debate del momento se centra en si somos capaces de construir un proyecto de nación homogénea, qué se está entendiendo por homogeneidad y qué papel juega el indígena en este proceso, ¿puede incorporarse como ciudadano de plenos derecho?, ¿debe regenerarse psicológica y moralmente y redimirse a través de la educación y el trabajo? o dado que es una raza inferior, ¿se debe plantear su exterminio o eugenesia para la mejora de la raza? ${ }^{67}$.

\footnotetext{
64 JUAREZ MUÑOZ [63] p. 49. Este mismo razonamiento es compartido por otros autores latinoamericanos, como Alcides Arguedas en Bolivia, o C.O. Bunge en Argentina. C.O. BungE, Nuestra América, ensayo de psicología social, Madrid, Espasa Calpe, $7^{\text {a }}$ edición, 1926.

65 JUAREZ MUÑOZ [63], p. 50.

66 ASTURIAS, [59], p. 57.

67 Las preguntas aparecen muy claramente definidas en toda la época y no encontramos ninguna de ellas que aluda a un proyecto de mestizaje como elemento configurador de la identidad
} 
Es en este punto donde nos queremos detener para retomar nuestra hipótesis inicial sobre la incapacidad que tuvimos los guatemaltecos de pensar o imaginar un proyecto de nación mestiza en la década de 1920 y 1930. En otros términos, no fuimos capaces durante este período de pensar en un proyecto de nación homogénea ${ }^{68}$, como lo hicieran otros compatriotas latinoamericanos. A nuestro juicio, fue la coyuntura histórica de las dictaduras de Estrada Cabrera y Ubico y la influencia de los pensadores de la Generación del 20, muy condicionados por el positivismo y las corrientes racialistas de la época, lo que obstaculizó la construcción de un proyecto de Nación Mestiza. Fue esa repugnancia por el mestizaje, por el cruce de razas, esa desvalorización de lo mestizo, como raza inferior, impura o degradada lo que obstaculizó la búsqueda de soluciones que crearan una conciencia de identidad nacional.

Partiendo del supuesto de inviabilidad del ladino y del mestizo, como sujeto histórico y cultural para la conformación de la identidad nacional, se recurre a las corrientes de la eugenesia para buscar una solución al «problema del indio». Esta corriente va a influir notablemente en la polarización de la sociedad en categorías antagónicas indio-ladino, en el imaginario acerca del temor hacia el indio sublevado y en su deseo de exterminio, pero sobre todo, en la incapacidad de imaginar un proyecto de nación mestiza. Durante el período estudiado el mestizaje y la ladinización, como proyectos, quedan descartados. y se discuten nuevas fórmulas de integración, exclusión o exterminio del indio.

\section{LA ASIMILACIÓN BIOLÓGICA DEL INDIO POR MEDIO DE LA EUGENESIA.}

Asturias siguiendo las teorías sobre la degeneración de las razas por la degradación de la sangre, plantea la premisa gobineana sobre la relación entre raza y nación. Tomando como ejemplos el argentino y el norteamericano, considera que la relación entre ambas es una relación de sangre y no de cultura. En esta línea, Asturias se inclina claramente por la mejora de la raza a través de la fusión con

nacional. Altamirano dice ¿será cierto que los hispanoamericanos somos incapaces de construir una nación culta y civilizada? AlTAMIRANO [62] p. 59. Muñoz dice «Guatemala no será nunca una nación, si no resuelve el problema del indio, como debe». JUAREZ MUÑOZ [63], p. 2. Asturias opina, «Para resolver el problema actual del indio, a la par que abrir escuelas, se necesita transfundir sangre nueva en sus venas....Sangre nueva he ahí la divisa». ASTURIAS [ 50] p. 55.

68 Por nación homogénea no estamos entendiendo lo que los autores de la época defienden como una nación «racialmente homogénea» o por la idea de una homogeneización racial por la vía del mestizaje. Entendemos el proceso histórico político ocurrido entre 1920 y 1930 de intentar la integración del indígena y hacerlo ciudadano y miembro de la nación. Un intento de valoración e integración de los valores indígenas para la construcción de un proyecto nacional, de síntesis cultural. Mónica QuiJADA, «La nación reformulada: México, Perú y Argentina 1900-1930 en Antonio ANNINO, Luis CASTRO y François Xavier GuERRA, De los Imperios a las Naciones: Iberoamérica, Madrid, Ibercaja, 1994, pp. 567-581; y QUIJADA [1]

R. I., 1999 , n. $^{\circ} 217$ 
sangre nueva que revitalice la indígena y lo expone en los siguientes términos: «Se trata de una raza agotada y de ahí que para salvarla, antes de una reacción económica, psicológica o educacional, haya necesidad de una reacción biológica ¡ vida, sangre, juventud, eso hace falta al indio! 69

Gustave Le Bon, a quien cita un par de veces en su tesis, y Manuel Gamio, a quien no cita, pero conoce por su estancia en Guatemala durante este período, propone como solución para el país la eugenesia. Plantea seleccionar las razas en función de los rasgos físicos, psicológicos y ambientales, a efecto de que puedan infundir en la raza india esos caracteres hereditarios para mejorarla. A su juicio, los inmigrantes que tendrían más éxito en el cruzamiento serían lo suizos, alemanes de Baviera y del Tirol. Su propuesta es clara «Para resolver el problema actual del indio, al par que abrir escuelas, se necesita transfundir sangre nueva en sus venas.... Sangre nueva, he ahí la divisa» ${ }^{70}$.

No es la única propuesta en esta dirección, otros autores, como Horacio Altamirano, Carlos Fletes Sáenz y Rafael Arévalo Martínez y César Brañas, entre otros, escriben artículos en revistas y periódicos que abogan por esa solución para remediar los males que aquejan al país ${ }^{71}$.

Resulta difícil en esta etapa invisibilizar a los indígenas como en el pasado, no resulta fácil omitir su presencia y su protagonismo después de la revolución mexicana, no parece razonable retrasar por más tiempo la formación de la nación en un momento cuando otras experiencias como la boliviana, peruana, brasileña o mexicana, están llevando experiencias similares de búsqueda de la identidad nacional. Resulta difícil no reflexionar en este período sobre los fundamentos de la nación, en un país en donde raza y etnia, raza y nación se encuentran estrechamente unidos.

Sin lugar a dudas son múltiples las soluciones apuntadas por la generación del 20, pero el proyecto de nación eugenésica surge vinculado a las dictaduras de Estrada Cabrera y de Ubico, a las elites intelectuales y de poder procedentes de la generación del 20 , quienes en un porcentaje representativo apostaron por el blanqueamiento de la nación y la regeneración del indio mediante su cruzamiento.

Esta narrativa va a facilitar la exclusión de los indígenas como ciudadanos y electores al restringir el voto a todos aquellos que no sepan leer ni escribir en la constitución de 1921. A su vez, va a funcionar como un hábil mecanismo de jus-

69 ASTURIAS [59] p. 53.

70 AstURIAS [59] p. 53.

71 Sobre este tema véase la revista Studium ; Revista de Educación popular. H. PROWE, «El indio», I, 3, julio, 1903, pp. 42-45. Revista del Trabajo, julio, 1925 pp: 349-352, «Por el indio», así como todo el debate que se genera en el Diario de Centroamérica y en El Imparcial sobre la mejora de la raza del indio. Brañas en sus artículos en El Imparcial opina que el problema étnico se complica con la multiplicación del ladino degenerado, procedente del indio mestizado con razas pobres. Es uno de los partidarios de la inmigración selectiva de los europeos para mejorar la raza. El Imparcial, 16 de enero de 1930. 
tificación para la aplicación de la ley de mandamientos, de la ley de vagos y maleantes y de toda la reglamentación contra el indígena para seguir obteniendo mano de obra semi-gratuita; va a reforzar un sistema de dominación excluyente, autoritario y patriarcal, basado en la hegemonía de lo que Brañas denomina «la cultura del blanco», como una cultura y una raza superior ${ }^{72}$.

\section{LA INTEGRACIÓN POR LA REGENERACIÓN Y LA REDENCIÓN DEL INDIO}

Tal vez lo novedoso del pensamiento de J. Muñoz resida en su afán de salvar al indio, de regenerarlo y convertirlo en un actor de la nación, en un ciudadano de pleno derecho. El regeneracionismo es uno de los elementos que más unifican a la Generación del 20. Suponemos que por influjo de la Generación del 98 y posteriormente la del 27 , casi todos ellos muestran su preocupación por este tema y tratan de dar soluciones políticas, jurídicas y morales para devolverle su dignidad perdida.

Durante esta década, el debate sobre la redención del indígena en la prensa es bastante generalizado y va desde aquellos que siguiendo las premisas liberales de 1870 , vinculan instrucción a civilización y a redención, y continúan considerando que la escuela y la instrucción pública son los elementos determinantes para su redención y su regeneración como raza y como grupo social ${ }^{73}$, pasando por un grupo numerosos de articulistas que se pronuncian a favor del trabajo semiforzado como único medio para regenerar a «esa raza inferior». Esta posición constituye una de las corrientes de opinión más debatidas en los diarios de El Imparcial, Diario de Centroamérica y La Gaceta ${ }^{74}$.

A raíz de la creación de clubs unionistas para defender «la libertad del indio», que tiene lugar en toda la República durante la etapa de la Unión, a y que defendían «el reconocimiento por parte de todas las autoridades de la República del

72 Véase el prólogo de Cesar BRAÑAS a la segunda edición del libro de JUAREZ MUÑOZ [63], titulado ¿qué hacer con el indio y la nación?. Sólo el título resulta bastante sintomático de la posición del autor.

73 En 1927, el Congreso presenta al Ministerio de Educación Pública un proyecto nuevo para la castellanización del indio por medio de la Escuela rural preparatoria, con el fin de lograr «la regeneración de los indios». En Revista de Educación rural, julio, 1927, pp. 27 y 28. Joaquín RODAS M., «La raza indígena como factor de progreso social», en Revista de Educación, 8 y 9 , febrero, 1933, pp.375-378 y «La raza indígena como Factor de Progreso Nacional», en Revista de Educación, 10, mayo, 1933, pp. 506-508. «La incorporación del indio a la escuela», en La Gaceta. Organo de la institución policial, VI, 42, 11 de noviembre de 1928, pp. 349-353. «Por la castellanización del indio», en Revista de Educación rural, julio, 1927, pp. 97 y 98.

74 «La redención del indio y el incremento de nuestra producción agrícola», en Diario de Centroamérica, 9875, 13 de septiembre de 1915 .

R. I., $1999, \mathrm{n}^{\circ} 217$ 
derecho de ciudadanía del indio» ${ }^{75}$, los terratenientes plantean en la prensa que dominan, que la principal causa de degeneración del indio radica en su vagancia y haraganería, que la única forma de solucionar esto es imponer una ley de mandamientos que les obligue a trabajar, «sólo obligándoles a trabajar podrán redimirse y ser ciudadanos capaces de ejercer sus derechos y cumplir con sus deberes». El indio debe regenerarse a través del trabajo y para ello es necesario volver a establecer el servicio de trabajo obligatorio ${ }^{76}$.

Sin embargo, a partir de estas posiciones se va a perfilar una corriente de opinión contraria a la explotación de los indígenas, tratando de buscar nuevas fórmulas de incorporación del indígena a la ciudadanía desde su propia lengua, respetando su cultura y evitando su explotación . En este contexto se va a inscribir el pensamiento de Juárez Muñoz.

Juárez Muñoz rompe con el determinismo de su primera época y propone la redención del indio por medio de la educación, de una legislación especial, unas leyes protectoras hasta alcanzar su nivelación en materia de trabajo, sanidad e instrucción. Pero lo más novedoso resulta la ley de adquisición de tierras. Según Muñoz, el indio puede regenerarse, redimirse y formar parte de la nación si se le incorpora plenamente al ejercicio de la ciudadanía a través de la adquisición de la tierra ${ }^{77}$.

Influido quizá por el pensamiento mexicano de Justo Sierra, cree que la educación, una legislación adecuada y específica de recuperación de sus costumbres y su religión, pero sobre todo, en la línea de Molina Enríquez, piensa que la condición indispensable para adquirir todos sus derechos es la recuperación de la tierra laborable. Solo así el indígena recuperará su anhelo de libertad y autonomía, su deseo de defender su propiedad y así generará una conciencia que le permita constituirse en «una positiva nacionalidad».

El hecho de plantear desde primeros de siglo y sobre todo durante la dictadura de Cabrera y posteriormente de Ubico, dar tierras a los indígenas, abolir los mandamientos y la ley de vagos y maleantes, supone una posición innovadora, frente a la corriente eugenésica o de exterminio del indio. El hecho de no proponer una vía intermedia, como la ladinización o asimilación del indígena a la cul-

75 Véase la creación de los Clubs sobre «la libertad del Indio, en Diario de Centroamérica, 10 de mayo de 1920. Y el articulo de Wade KIT, «The unionist experiment in Guatemala. 1920-1921: Conciliation, desintegration, and the liberal Junta», en The Americas, L (1), julio, 1993, pp. 31-64.

76 Véase Diario de Centroamérica, 10 de mayo, 1920, 17 de junio,1920, 1 de julio 1920. Sobre este tema, Julio Castellano Cambranes, Coffee and peasants in Guatemala, South Woodstock, VT, 1985.(Edición española Café y campesinos en Guatemala 1853-1897, USAC, 1985).

77 Para Muñoz, «Cuando al indio se le considere tratado de diferente manera de cómo lo es en la actualidad en su difícil problema del trabajo; cuando note que tiene derechos que le son respetados y que se le concede un puesto en el convivir social, que ya no es paria, que se le toma en consideración, que ya no es cosa, sino un ser humano con sentimiento y voluntad, con aspiraciones y anhelos, a la cual engrandece con su fuerza de su músculo y fecunda con el dolor de su frente, entonces habremos hecho el milagro de incorporarlo a nuestra civilización porque entonces será nuestro hermano», JUAREZ MUÑOZ [63], pp. 142 y 143. 
tura occidental, sino el respeto a la cultura, a sus costumbres y a partir de ahí incorporarlos como ciudadanos, en un acto indispensable de configuración de lo que él denomina «una nacionalidad positiva», supone un pensamiento revolucionario para su época.

Resulta curioso que Muñoz, conocedor del pensamiento mexicano, no recurra a las teorías de la mestizofilia y no plantee la solución del problema indígena a través de la creación o de la fusión en el mestizo, como síntesis cultural; tampoco parece ser partidario, como Riva Palacios, de considerar el mestizaje como la síntesis de la mexicanidad, ni sugiere que sea el ladino el sujeto histórico llamado a fundar la identidad nacional ${ }^{78}$. Ni siquiera parece considerar, en ninguno de sus dos libros, que el mestizo sea el llamado a formar la nacionalidad guatemalteca, como lo plantea Molina Enríquez y tanto autores mexicanos y peruanos. Mucho menos toma las tesis de Vasconcelos, ya conocidas y divulgadas en el vecino país, sobre la quinta raza, la raza cósmica, una síntesis superior salvadora de la humanidad y destinada a sustituir a la raza blanca ${ }^{79}$.

Para nuestro autor la exaltación del mestizaje o de la ladinidad, no fue el modelo ni el camino sugerido para la formulación de un proyecto de nación homogénea. Tampoco lo fue para otros autores de la época como M.A. Asturias, H. Espinosa Altamirano o E. Quintana o C. Brañas.

Muñoz considera que el indígena debe ser incorporado al progreso y a la civilización desde su propia cultura e identidad, a través de una educación, de una legislación que impida los abusos y los males que le aquejan: el alcohol, las enfermedades, el excesivo trabajo, la ausencia de tierra. Su contribución para la época es plantear una legislación especial para este colectivo que le garantice plenamente «su condición de ciudadanos», vinculando la adquisición de la ciudadanía a la posesión de la tierra. Estas medidas son, a su juicio, la mejor forma de sacar al indígena de su atraso y marginación.

78 En esta segunda parte del libro la influencia de autores mexicanos es muy fuerte, ya Vicente Riva Palacios en el Contrato social, hablaba de la creación de un pueblo único y de una nacionalidad propia basada en una raza, los mestizos. También Molina Enríquez pensaba que la redención del indio no era posible si no se hacía un reparto de tierras. Sobre este tema la obra de A. BESAVE BENITEZ, México Mestizo, Análisis del nacionalismo mexicano, en torno a la mestizofilia de Andrés Molina Enriquez, México, FCE, 1992, as como la obra de D. BRADING, Los orígenes del nacionalismo mexicano, México ERA,1983.

79 Molina Enríquez, revirtiendo las tesis racialistas de la degeneración de la fusión de sangres, considera que el mestizo es una raza superior a la española e indígena, por tener una mayor energía y vitalidad y por saberse adaptar mejor que los otros dos grupos raciales.» Por ello es por lo que el mestizo prevalecerá e impondrá la nacionalidad mexicana». El mestizo a su juicio es el hombre destinado a detentar el poder de México. Las tesis Molinianas serán llevadas a su máximo exponente con Vasconcelos para quien, fruto de la feliz fusión entre españoles e indígenas se engendrará una nueva síntesis superior a la anterior, la raza cósmica, en palabras textuales, «es esta mezcla de sangres, es esta fusión de estirpes donde debemos de buscar el rasgo fundamental de la idiosincracia iberoamericana», p. 29. en J. VASCONCELOS, La raza cósmica, México, Espasa Calpe, 1996.

R. I., $1999, \mathrm{n}^{\circ} 217$ 
Este planteamiento difiere sustancialmente del de la nación homogénea, por medio del mestizaje y de la hibridación cultural. No hay ninguna mención al hecho de que a la homogeneidad se llegue por un proceso de ladinización y que éste sea el modelo político homogéneo, tras el triunfo del Estado liberal, como opinan Taracena y Rodas ${ }^{80}$.

Frente a los partidarios de la nación eugenésica, del exterminio o de la invisibilización de la raza indígena; frente a los partidarios del blanqueamiento de la nación hegemonizada por el grupo blanco-criollo en el poder tal y como proponían algunos intelectuales de la dictadura ubiquista, Juárez Muñoz se alza con una propuesta novedosa y renovadora para su época a contrapelo de las teorías racistas en boga y pienso que, salvando las distancias podemos denominarlo como un proyecto de nación multicultural.

En este proyecto, al indígena no se le extermina, ni se le integra, ni se le ladiniza, el vocablo no aparece ni una sola vez mencionado, se le incorpora y esto se logra haciéndole partícipe de todos sus derechos de ciudadanía. Lo que quiere Juárez Muñoz es que dejen de ser ciudadanos imaginarios y de estar formalmente homologados por las mismas leyes sin que ello suponga en la práctica el gozar de los mismos derechos; lo más importante es que considera que esta ciudadanía debe de estar fundamentada en la elaboración de una legislación especial que frene los abusos, remedie los males del pasado y garantice a los indígenas derechos específicos como puede ser la educación en su propio idioma, un respeto a sus costumbres y a su cultura, una profunda tolerancia hacia su cultura y su religión.

A nuestro juicio, Juárez Muñoz abrió una ventana nueva en la corriente de pensamiento de la época que fue escasamente escuchada en las décadas del 1920 y 1930, pero que tuvo mucha audiencia en 1944 y fue muy valorada por los intelectuales de la revolución de Octubre, sobre todo por su propuesta de reforma agraria. Este planteamiento, en el contexto en el que fue escrito y defendido supuso enfrentarse a los proyectos eugenésicos o a las teorías de la nación étnicamente blanca, tan en boga durante este período. A pesar de todo no pudo sustraerse de la excesiva influencia del racialismo decimonónico y del positivismo Spenceriano, pero sí fue capaz de dar un salto en lo referente a su imaginario de nación y sobre todo a las soluciones propuestas para enfrentar «el problema del indio».

\section{EL DEBATE ACTUAL SOBRE «LOS MAYAS Y LA NACIÓN»}

Si bien es verdad que en las postrimerías del siglo XX los términos del debate se han modificado, lo que también resulta evidente son las reminiscencias del liberalismo decimonónico y del pensamiento racial en las elites intelectuales ladinas; lo más sorprendente aún es que los escasos mecanismos de integración e

80 RoDAS [73] y TARACENA [7]. 
inclusión que se perfilaban a principio del siglo, parecen haberse reducido y haber aumentado los espacios del racismo.

La polémica sobre «el indio y la nación» se reanuda con motivo de los Acuerdos de Paz y se intensifica a raíz de la consulta popular del referéndum sobre las reformas constitucionales. Los argumentos que se emplearon, a favor del «sí» o del «no» a las enmiendas constitucionales, nos permiten retomar el tema que venimos tratando y observar cuál es el posicionamiento de los diversos actores sociales al respecto. Nos centraremos en los argumentos del «no» por considerar que en ellos se refleja gran parte de los imaginarios «nacionales» del presente y resabios del pasado colonial y liberal ${ }^{81}$.

El principal argumento en contra de las reformas es el de la igualdad ante la ley y el respeto a la constitución, a «los derechos consagrados en la Carta Magna». «Votar «sí» es atentar contra la constitución y crear un caos político», opina Carlos Toriello, «las reformas atentan contra los derechos, consagrados en la Constitución, de las personas, de la vida y de la propiedad e igualdad», opina Marta Yolanda Díaz Durán, «violan el principio de igualdad de todos frente a la ley concediendo privilegios a los indígenas» 82 . El concepto de privilegio de los indígenas, ante las reformas constitucionales, es propio de toda la etapa liberal que criticaba la legislación colonial y a los conservadores por fomentar las desigualdades y promover la sociedad de castas. Sin embargo, ninguno de los defensores de la igualdad plantea que en la práctica estos derechos se violan permanentemente y que en la mayor parte de los casos la población indígena se encuentra social, económica y políticamente excluida.

El segundo argumento de la consulta popular en su vertiente más simplista y reduccionista es considerar que la nación no existe; que tratar de construirla es inviable, porque ya lo intentaron los regímenes totalitarios, el nazismo y el stalinismo y fracasaron. Lo que se debe retomar es la patria, porque «es de todos». Retornando a viejos imaginarios coloniales y liberales, consideran que «la nación y los derechos culturales sólo les interesan a los mayas», porque lo que pretenden es dividir el Estado. Los mayas, opina Palmieri, «nos quieren arrebatar la pa-

81 Para la elaboración de este análisis se han seleccionado los artículos de opinión y los editoriales de los principales diarios del país, El Gráfico, La Hora, Siglo XXI, Prensa Libre, El Periódico y de algunas revistas,como Panorama y Crónica, así como el resultado o las conclusiones de seminarios, talleres y mesas redondas que se hicieron al respecto de febrero al 16 de mayo de este año. Fecha en que se celebró la consulta.

82 Julio César ToRIEllo, El Periódico, 16 de abril,1999,. Marta Yolanda Díaz Durán, Siglo XXI, 6 y 9 de mayo 1999. Estos dos articulistas son descendientes de la principales redes familiares de la oligarquía y se encuentran unificados en una agrupación neoliberal llamada «Liga Propatria», a la que también pertenecen Jorge Palmieri y Francisco Bianchi Castillo. Este último, pastor del Verbo y dirigente máximo de los evangélicos neopentecostales, agrupados en torno a la «Cruzada cívica por el no».

R. I., 1999, n. $^{\circ} 217$ 
tria»... quieren dividir el Estado.... Guatemala no es de los indígenas, es de todos, aunque no corra sangre maya por nuestras venas» ${ }^{83}$.

Es en este discurso donde yo considero que se encuentra uno de los puntos nodales de exclusión social de la población indígena. Seguir considerando que el Estado, «la Patria» y la Constitución son espacios reservados a los criollos y ladinos. Las comunidades y ese «ente» inexistente e innecesario que es «la nación», les corresponde a «los indios». En sus argumentos no existen espacios interculturales en donde se pueda o deba generar una identidad nacional.

Resulta sorprendente no encontrar, en el discurso del «no», argumentos que mencionen la existencia de discriminación étnica o social hacia los indígenas, ni propuestas de incorporar o integrar a los indígenas en la ciudadanía; mucho menos de crear una nación mestiza. Ninguno de los comentaristas analizados utiliza el término nación, todos hablan de patria refiriéndose a la «patria del criollo o al concepto liberal de patria «lugar donde nací y vivo», «lugar donde se criaron mis hijos»; en otras palabras, al territorio que me corresponde por nacimiento. Como escribe Palmieri «no se les vaya de las manos a los indígenas creerse los legítimos herederos y únicos dueños del país».

Continúan partiendo del supuesto que el Estado y la Constitución son espacios reservados a los blancos, criollos o ladinos y que los mayas, al querer formar «su propia nación, con sus lenguas, costumbres y derechos culturales», lo que quieren hacer es «dividir al Estado». Como dice un columnista, «pretenden dividir al país con el reconocimiento de sus lenguas, derecho consuetudinario y lugares sagrados....los mayas con esos privilegios quieren una guerra étnica y convertir a Guatemala en Kosovo» ${ }^{84}$.

Dado que para estas elites la nación no existe, ni debe constituirse, que la patria es de los criollo-ladinos y los mayas vulneran la unidad del Estado nación ¿qué sentido tiene incorporar sus derechos diferenciados que atentan contra la igualdad ante la ley y contra el Estado de derecho y la Constitución?

Este discurso es más excluyente y menos integrador que el de principios de siglo y está legitimado en los principios liberales de los derechos universales de la ciudadanía común contemplados en la carta Magna. La posibilidad de incorporar los derechos culturales de la mayoría del país, los mayas, no sólo es impensable : es ilegal y viola los principios de igualdad, libertad y derechos de la propiedad, porque crea privilegios de un grupo frente a otro. Este es el argumento más utilizado a los largo de la campaña.

\footnotetext{
83 Jorge PALMIERI, Editorial Siglo XXI , «Gana Guatemala» 18 de mayo de 1999. Luis Enrique PÉREZ, «El liberalismo y la igualdad ante la ley, Siglo XXI, 8 de mayo de 1999.

84 Editorial, Siglo XXI, 1 de mayo 1999. Para Luis Enrique Pérez, «los racistas son los mayas y la votación del «no» supone rechazar un Estado racista, un Estado que clasifica a sus ciudadanos según su raza y origen étnico y un Estado que favorece los privilegios». Por eso votar no supone «defender la constitución y la igualdad», Siglo XXI, 19 de mayo de 1999.
} 
Resulta interesante observar que en casi ninguno de los discursos, tanto del sí como del no, hay referencias sobre la construcción de un proyecto homogéneo, ni mucho menos de una identidad nacional basada en el mestizaje, ni siquiera se menciona el problema de la nación o de la identidad nacional como ocurría a principios de siglo. La nacionalidad la tenemos todos por ser Guatemaltecos, como ciudadanos iguales ante la ley.

También los resabios liberales emergen en el imaginario de estas elites al plantear un Estado dual, con dos grupos enfrentados, indígenas y ladinos en los que «los mayas quieren sacar provecho de los Acuerdos de Paz y quieren dividir Guatemala con el apoyo internacional». La dicotomía indígena-ladino vuelve a emerger como una categoría bipolar y excluyente y el estereotipo del «indio» se refuerza con el imaginario del «maya» que quiere «destruir el Estado y arrebatarnos el poder». Esta dualidad se manifiesta en la discusión sobre dos tipos de ciudadanía, la de aquellos que quieren el bien común, la igualdad y la paz, frente a aquellos que quieren una ciudadanía diferenciada, pretenden tener privilegios y quieren un nuevo conflicto, la guerra étnica. El artículo de Luis Enrique Pérez, titulado «las dos ciudadanías» resulta muy esclarecedor. Haciendo un llamamiento al «no», argumenta. «... Si Ud. quiere que sólo los ciudadanos ladinos hablen el español, vayan de uniforme al colegio, se sometan a las autoridades ordinarias y a las leyes penales, mientras los indígenas se les libera de todas estas obligaciones, Vote SI. Si quiere que los mayas formen su propia nación, posean su propio derecho consuetudinario y tengan su propio territorio, VOTE SI... «Pero si no quiere que la nación se divida, que los indígenas se apoderen de sus propiedades, que no hayan ciudadanos de segunda categoría y que gane un grupo de políticos comprometidos con los guerrilleros y con intereses foráneos, Vote «no», para evitar que se vaya a la guerra racial» 85 .

Podemos concluir afirmando que «el problema del indio y de la nación» continúa siendo un debate inacabado y sin resolver y que de nuevo, hemos perdido una gran oportunidad que nos brindaban los acuerdos de Paz y la consulta popular para reformular un proyecto de nación más incluyente y homogénea en la que todos nos sintamos representados.

This article studies the ideas of a number of 19th and 20th Century political thinkers in regard to national projects which were inclusive or exclusive of subordinate groups such as Indians and Ladinos. The 19th Century inclusive position of José Cecilio del Valle and the more exclusive one conceived by Batres Jauregui are analyzed, as well as the reasons why these types of ideas are still prevailing. In the 20th Century, the analysis includes exclusion defenders such as Horacio Altamirano and their opposites, like Juárez Muñoz.

85 Luis Pérez, Siglo XXI, 29 de abril de 1999.

R. I., $1999, \mathrm{n}^{\circ} 217$ 
The whole article is pervaded with the ideas of the so called Generacion del 20, the analysis of which is particularly original and important to understand arguments which have prevailed till the present day and are used to support theories for the inclusion and/or exclusion of Indians in the nation project of Guatemala. 